\title{
Mapping Korea's International Linkages using Generalised Connectedness Measures
}

\author{
Hail Park* \\ Yongcheol Shin**
}

The views expressed herein are those of authors and do not necessarily reflect the official views of the Bank of Korea. When reporting or citing this paper, the authors name should al ways be explicitly stated.

\footnotetext{
* Economic Research Institute, Bank of Korea, 39, Namdaemunno, Jung-Gu, Seoul, 100-794, Republic of Korea, Email: bluechip@bok.or.kr

** Department of Economics and Related Studies, University of York, Heslington, York, YO10 5DD, UK. Email: yongcheol.shin@york.ac.uk. Tel: +44(0)1904 433757.
}

We are grateful for the helpful comments of Woon Gyu Choi and Junhan Kim and for the discussion of seminar participants at the Bank of Korea and University of York. In particular, we are greatly indebted to Matthew Greenwood-Nimmo and Viet Ngyuen who kindly help us to construct all of the figures and tables in this paper. They also provide further constructive and valuable comments. Any remaining errors or omissions are the responsibility of the authors. 


\section{Contents}

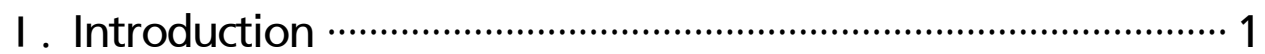

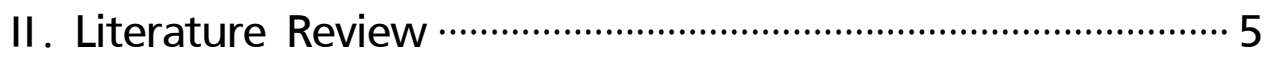

III. Empirical Methodology ………………………………........ 9

3.1 The Global Vector Autoregressive (GVAR) Model …………………... 9

3.2 Generalised Connectedness Measures (GCMs) …………………….... 12

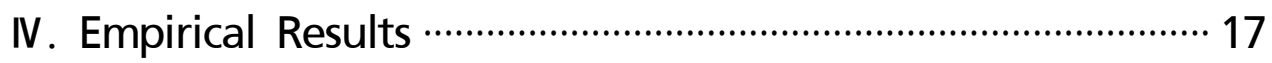

4.1 Pre-Crisis Average Connectedness, 1980-2007 ……………………... 17

4.2 Recursive Sample Analysis of Spillover Dynamics, 2005-2012 … 38

V. Concluding Remarks ……................................................. 43

References 


\section{Mapping Korea's International Linkages using Generalised Connectedness Measures}

Korea is a textbook example of a small open economy which is susceptible to conditions overseas but cannot affect them itself. Policymakers in Korea would therefore naturally benefit from an enriched understanding of the connections that exist between the Korean and global economies. We provide a detailed summary of these linkages using the generalised connectedness methodology introduced by Greenwood-Nimmo, Nguyen and Shin (2013b). Among our principal findings is the observation that domestic conditions are only generally important in the short to medium term, with overseas conditions exerting a dominant influence on Korea's economic prospects in the long run. The economies which exert the strongest effect on Korea are the US, Europe, China and the ASEAN group, with a considerable role also played by global energy markets. Furthermore, we find that the ongoing global financial crisis is assodiated with greater connectedness of the Korean economy with advanced economies and its reduced connectedness with emerging economies.

Keywords: Small Open Economy of Korea, Global VAR, Forecast Error Variance Decomposition, Generalised Connectedness Measures.

JEL Classification: C32, C53, E17. 


\section{Introduction}

Recent decades have seen the development of deep and complex international linkages between economies and markets throughout the globe. Arguably, much of this change has been rooted in deregulation and liberalisation, spatial specialisation in production and a succession of revolutionary advances in information and communications technologies. As a result, the economies of the world are now more intricately interconnected than they have ever been. On one hand, such an interconnected system promotes shared prosperity. On the other, it means that shocks can spread rapidly and forcefully through the global economic and financial system in a way that would not have been possible in the past. As such, the study of open economy macro and financial economics has gained a fresh impetus, at the heart of which is interest in modelling the connections that link entities in the global economy.

Due to its economic and political history in recent decades, Korea is likely to exhibit strong connections to many of the World's dominant markets, notably the US, EU, Japan and China. Moreover, as became apparent during the Asian banking crisis, Korea is strongly connected to its regional peers. It therefore provides an excellent example of a small open economy which will be subject to a variety of foreign shocks but which is unlikely to transmit shocks beyond countries in its immediate vicinity. Moreover, given the gradual shift in prominence among the major global powers, it is reasonable to expect that the connectedness of the Korean economy may exhibit considerable and economically important timevariation. I ndeed, Figure 1 reveals that trade relative to GDP has steadily increased between 1980 and 2012, while finandial linkages measured by holdings of foreign financial assets and liabilities have increased rapidly over the same period, and especially since the 1997 Asian financial crisis. 
Figure 1: Economic Openness in Korea (expressed as a percentage of GDP)

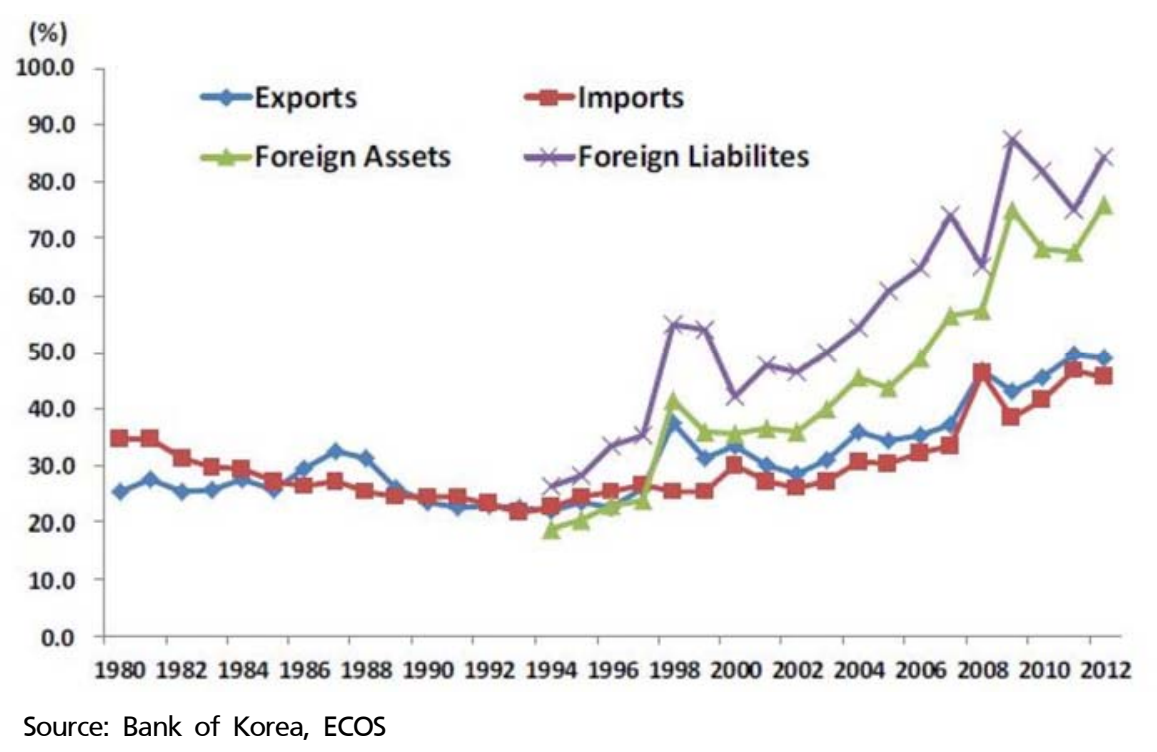

In light of such trends, there is an increasingly pressing need to explicitly model the nature and extent of global interlinkages and to refine our understanding of the channels through which shocks are propagated in the global economic and financial system. Consequently, academic economists and practitioners alike are increasingly stressing the importance of the quantifying global connectedness to inform policymaking and risk management activities at both the national and supra-national levels. I ndeed, as noted by Pesaran and Smith (2006), "[i]nternational economic interdependence means that national economic issues have to be considered from a global perspective." In the absence of a proper understanding of these international forces, policymakers are poorly placed to cope with global shocks and crises, a lesson that was emphatically underscored by the 2007-8 Global Financial Crisis and the ensuing European Debt Crisis.

As international linkages become stronger and more diverse, overseas conditions will naturally come to play an increasingly important role in sovereign policy formulation. However, the prevailing consensus regarding the conduct of stabilisation policy emphasises the use of monetary policy to guide the economy toward a desired equilibrium via manipulation of the nominal overnight interest 
rate in an optimal manner in light of selected domestic indicators. Following the seminal work of Taylor (1993), the most widely used indicators to be found in the literature are the rate of pricelevel inflation and the output gap. While these variables will indirectly convey some information about overseas conditions, the question of how one should directly account for the influence of foreign variables on domestic policy remains open.

We approach this issue using the Generalised Connectedness Measures (GCMs) introduced by Greenwood-Nimmo, Nguyen and Shin (2013b, GNS), which represent a generalisation of the connectedness methodology developed by Diebold and Yilmaz (2009, 2014). The key feature of this methodology is that it is "simple and intuitive, yet rigorous and replicable" (Diebold and Yilmaz, 2009, p. 158). The essence of the GCM methodology is to compute and cross-tabulate forecast error variance decompositions for a dynamic multivariate model in order to construct a weighted directional network that may be used to quantify spillover effects between entities in the model. The key innovation of GNS (2013b) is to extend the simple connectedness methodology of Diebold and Yilmaz (DY) to the context of global VAR models, thereby creating a powerful tool for the dynamic analysis of global interlinkages.

The GCM framework generalises the DY approach in at two critically important ways. Firstly, GCMs preserve information losslessly across multiple horizons. Secondly, they are robust to both variable re-ordering and aggregation. These features are of central importance when measuring connectedness in a truly dynamic fashion in a multi-country multi-variable framework. GNS (2013b) highlight a variety of important features of the GCM framework, including their ease of computation using standard software solutions, their transparency and ease of replication, their model-independent nature which accommodates both structural and reduced form applications and their straightforward and intuitive interpretation which does not require the audience to be well acquainted with anything but basic economic concepts. The GCM approach therefore represents a natural and highly adaptable framework for the analysis of international linkages, particularly where one intends that the results should be accessible to nonspecialist audiences. 
The starting point for our analysis is the 26 country/176 variable GNS GVAR model developed by GNS (2012a). To establish a baseline, we replicate the estimation results in that paper over the period 1980q2-2007q2 and then compute GCMs using the estimated coefficients and covariance matrices. We refer to these benchmark GCMs as our full sample results, and interpret them as a general representation of the average connectedness of the Korean economy over the estimation period. Among our principal findings is the observation that domestic conditions are only generally important in the short to medium term, with overseas conditions exerting a dominant influence on Korea's economic prospects in the long run. Furthermore, we find that the economies which exert the strongest effect on Korea are the US, China and the ASEAN group, with a considerable role also played by global energy markets.

We then conduct recursive estimation over 30 samples starting with 1980q2-2005q2 and ending with 1980q2-2012q3. This allows us to trace how the international linkages of the Korean economy evolved during the Great Recession. Interestingly, we find that the GFC is associated with greater connectedness of the Korean economy with advanced economies and its reduced connectedness with emerging economies. These results can be explained partially by the interplay between increased volatility of the global financial markets mainly driven by unprecedented monetary policy such as the quantitative easing conducted by the US, the EU and Japan, and the macro-prudential policies adopted by emerging countries to stabilise their external balances.

The paper proceeds as follows. Section 2 briefly outlines the existing literature on global macroeconometric modelling. Section 3 introduces the GCM approach developed by GNS (2013b) and describes the framework for measuring global connectedness. Section 4 presents the main empirical results and the policy implications. Section 5 condudes. 


\section{Literature Review}

Recent advances in the construction of multi-country and global macroeconomic models have opened new possibilities for the study of cross-border economic and financial linkages and spillover effects. Two principal modelling strategies have emerged as the preferred tools for analysis in this growing literature: multi-country dynamic stochastic general equilibrium (DSGE) models, and global vector autoregressive (GVAR) models.1) As a crude generalisation, these frameworks can be viewed as trading off rich microfoundations against straightforward scalability and ease of estimation. While DSGE models are richly microfounded and incorporate sophisticated intertemporal optimisation behaviour, this very sophistication places a natural limit on the feasible size of the system. Consequently, existing DSGE models are not truly global as they only consider a small number of economies which are calibrated to provide a highly stylised representation of selected key players in the global economy. Examples indude the IMF's Global Economy Model (GEM), Global Fiscal Model (GFM) and Global Projection Model (GPM) which are surveyed by Carabenciov et al. (2008).

By contrast, GVAR models are built by aggregating a number of countryspecific VAR models into a global system; as such, they are highly scalable.2) The

1) In the aftermath of the global financial orisis, the IMF provides a comprehensive report documenting popular methods to measure systemic linkages among financial institutions (Global Financial Stability Report, April 2009). These methods used are: (i) the network approach, (ii) the co-risk model, (iii) the distress dependence matrix, and (iv) the default insensitive model. Several studies have also attempted to analyse the comovement and interconnectedness among the multiple financial markets. Eichengreen et al. (2012) find that the interdependencies among global banks' CDS spreads have been significantly strengthened during the subprime crisis in 2007, indicating the strong spillover effects from the US fi nancial market to the global financial system. Fong and Wong (2012) examine the financial interconnectedness among 11 Asia-Pacific countries by applying the CoVaR methodology to the CDS data, and they show that every country under consideration tends to exhibit the higher sovereign risk conditional on that another country is under turmoil circumstances. Diverse and useful as they are, however, these approaches only focus on the financial sector without explicitly accounting for the interactions between financial and real sectors. It is not dear how these shortcomings can be resolved within the set-ups of these methods.

2) GVAR models can be viewed as a generalisation of panel VAR (PVAR). PVAR models have been applied to multicoutry analysis, with recent examples induding Anderson, Qian, and Rasche (2006), Goodhart and Hofmann (2008), and Assenmacher-Wesche and Gerlach (2008). PVAR achieves efficiency gains relative to country-specific VAR and also uncovers common dynamic relationships which may otherwise 
essential innovation of GVAR is the introduction of an explicit linking scheme through the construction of country-specific foreign variables as weighted averages of the variables in the global economy. By exploiting these linkages, countryspecific models may be combined consistently into a global simultaneous equation system (Pesaran, Schuermann and Weiner, 2004, PSW; Dees, di Mauro, Pesaran and Smith, 2007, DdPS; Dees, Holly, Pesaran and Smith, 2007, DHPS). GVAR models have been applied to the analysis of business cycle linkages (e.g. DdPS; DHPS), financial contagion and spillovers (e.g. PSW; Chen et al., 2009; Sgherri and Galesi, 2009) and global trade and current account imbalances (e.g. Bussière et al., 2009; GNS, 2012a and 2012b).3) However, as a result of their often considerable size, existing applications have generally confined their attention to reduced-form representations.

The standard tools of dynamic analysis induding impulse response functions (IRFs) and forecast error variance decompositions (FEVDs) can be used with both DSGE and GVAR models. However, as models become larger, the presentation and interpretation of these dynamic tools becomes increasingly selective, potentially obscuring the broader nature of interlinkages embodied in the model. Until recently, little research effort had been dedicated to the construction of non-selective summary measures appropriate for use with such large models. This is where the GCM approach enjoys a singular advantage.

The development of GCMs represents a generalisation of the connectedness measures proposed by Diebold and Yilmaz (2009, 2014, DY). In their 2009 paper, the authors lay the foundations for a simple and intuitive measure of interde-

be obscured by idiosyncratic variation at the country-spedific level. However, the usual reliance on pooling restrictions disregards country-spedific dynamics and cross-country interdependencies. This limitation can be overcome if one follows the reparameterisation/factorisation approach advanced by Canova et al. (2007). As demonstrated by Ciccarelli et al. (2012), the number of parameters in a multi-country model can be reduced by making use of various factors (or linear combinations) of regressors. Nevertheless, the choice of factorisation is naturally application-specific and thus somewhat ad hoc.

3) Among the more widely cited examples of the GVAR methodology, DdPS construct a system of 33 countries induding the long-and short-term interest rate, inflation, output, the exchange rate, the equity and oil prices to analyse business cycle linkages between the US and the Euro Area. Using impulseresponseanalysis, they show that financial shocks are transmitted more rapidly than real shocks and financial markets have a higher degree of synchronisation than real markets. 
pendence of asset returns/volatilities based on cross-tabulation of orthogonalised FEVDs derived from simple univariate VAR models. DY (2014) abandon orthogonalisation due to the order-variance of the Cholesky decomposition and develop a modified order-invariant version based on normalised generalised FEVDs following Pesaran and Shin (1998). However, GNS (2013b) demonstrate that this approach suffers from a number of significant drawbacks which limit its applicability to multi-country multi-variate models. Firstly, the normalisation routine used by DY (2014) involves a loss of information across horizons, hampering efforts at the dynamic analysis of connectedness. Furthermore, the DY framework only accommodates two levels of aggregation: full aggregation to measure overall spillovers in the system as whole and no aggregation to measure spillovers among individual variables. I ndeed, the DY method is not robust to the aggregation of variables into groups, a feature which is likely to be highly desirable in any model comprised of multiple countries each of which is described by multiple variables. Notice also that the DY connectedness measures are designed for the multicountry univariate or singlecountry multivariate cases. This is a severe limitation given that they stress that connectedness is "central to understanding underlying fundamental macroeconomic risks, in particular business cycle risk (intra-and inter-country real activity connectedness)."

There has been a small but growing number of studies on the large scale macroeconometric modelling of the Korean economy. Kim and Park (2009) employ the global structural VAR model and find that both Chines inflation hike and the depreciation of Yuan have played a significant role in influencing the Korean domestic economy. Choi et al. (2011) apply the GVAR approach to investigating the impacts of the capital inflows on economic growths for the four focus countries plus AESAN region (8 countries induding Korea). Employing the system of the six endogenous domestic variables (GDP, CPI, exchange rate, the equity price and the short-term nominal interest rates, and the two exogenous global factors (VIX and the global liquidity), they find that the sudden increase in the capital inflows, mainly caused by volatile global factors, has resulted in the significant slowdown of growth in the small emerging economies such as Korea.

However, this approach cannot provide the transmission mechanism of how the 
capital inflows affect real economy through interest rate and exchange rate channel. Choi et al. (2013) construct the GVAR model for 33 countries with the six endogenous domestic variables (productivity, inflation, asset price, exchange rate, the short-term interest and the long-term interest), and demonstrate that the forecasting performance of the GVAR model is quite satiffactory even after the GFC. Furthermore, they establish via the simulation studies that the (negative) influence of the deprediation of the Japanese Yen on the Korean economy has recently weakened, confirming the dedining trend of trades between Korea and Japan. Shin (2009) develops a small quarterly long-run structural national macroeconometric model for Korea. The model is estimated over the period 1982q3 $2006 \mathrm{q} 2$ in six endogenous domestic variables and three weakly exogenous foreign variables. Shin reports structural impulse response functions with respect to the shocks to oil price, foreign and domestic monetary policy. GNS (2012b) analyse the international linkages of the Korean economy using the GVAR model. By employing a combination of generalised impulse response analysis and forecast error variance decompositions, they uncover: the real economy and the financial markets are highly sensitive to the oil price; the dominant sources of overseas influence on the Korean economy are the US, the Eurozone, Japan and China; but, rather surprisingly, the interest rate is set largely without recourse to overseas conditions. However, all of these studies have suffered from the processing constraints inevitably associated with the large-scale models, which are prone to focus on selective presentation and interpretation of results. As highlighted above, this selectivity dearly obscures a broad picture of interlinkages of the Korean economy within the global system. 


\section{Empirical Methodology}

Our analysis of the connectedness of the Korean economy is based on the 26 country/176 variable GNS GVAR model on the basis of which we will compute GCMs. We briefly recap the derivation of the model and present a highly abridged discussion of the salient features of the GCM approach. For a detailed derivation of the GVAR model, see PSW, DdPS and GNS (2012a), and for further details on the construction and interpretation of GCMs, see GNS (2013b) as well as DY (2014) for earlier foundational work.

\subsection{The Global Vector Autoregressive (GVAR) Model}

The GNS-GVAR model is constructed by combining 26 country-specific $\operatorname{CVARX} *(2,2)$ models. Table 1 provides the set of countries, numbers of cointegrating relationships, numbers of endogenous and weakly exogenous variables, and included structural breaks in each model. The weakly exogenous foreign series denoted by an asterisk (e.g. $\left.y_{i t}^{*}\right)$ are computed as weighted averages of the data for the remaining $N-1$ countries as $y_{i t}^{*}=\Sigma_{j=1, j \neq i}^{N} \omega_{i j} y_{j t}$ where $\omega_{i j} \geq 0$ is the tradebased weight such that $\Sigma_{j=1}^{N} \omega_{i j}=0$ and $\omega_{i i}=0$.

In the majority of countries (i.e. $i=2,3, \ldots, 21$ ), the CVARX* models indude the following endogenous $I(1)$ variables: $\mathrm{y}_{i t}=\left(r e_{i t}, r_{i t}, i m_{i t}, e x_{i t}, q_{i t}, \Delta p_{i t}, y_{i t}\right)^{\prime}$, i. e. real effective exchange rate, short-term interest rate, real import, real export, real equity price, inflation and real output, respectively. Note that $r e_{i t}$ is the log real effective exchange rate defined as $r e_{i t}=e e_{i t}+p_{i t}^{*}-p_{i t}$ and $e e_{i t}+p_{i t}^{*}-p_{i t}=$ $\left(e_{i t}-p_{i t}\right)-\left(e_{i t}^{*}-p_{i t}^{*}\right)=\tilde{e}_{i t}-\tilde{e}_{i t}^{*}$, where $e_{i t}$ is the nominal exchange rate $v i s-\grave{a}-v i s$ the US\$, $e_{i t}^{*}=\Sigma_{j=1}^{N} \omega_{i j} e_{j t}, e e_{i t}=\Sigma_{j=1}^{N} \omega_{i j} e_{i j t}$ is the nominal effective exchange rate, $p_{i t}$ the national price level and $p_{i t}^{*}$ the foreign price level. Given data constraints, $\mathrm{y}_{i t}=\left(r e_{i t}, r_{i t}, i m_{i t}, e x_{i t}, \Delta p_{i t}, y_{i t}\right)^{\prime}$ for countries $i=22, \ldots, 25$, while $\mathrm{y}_{i t}=\left(r e_{i t}, i m_{i t}, e x_{i t}, \Delta p_{i t}, y_{i t}\right)$ for country $i=26$. For countries $i=2, \ldots, 26$, the vector of weakly exogenous $I(1)$ foreign variables is defined as $\mathrm{y}_{i t}^{*}=\left(p_{t}^{o}, r_{i t}^{*}, q_{i t}^{*}\right.$, 
Table 1: Details of the Specification of the GNS GVAR Model

\begin{tabular}{|c|c|c|c|c|c|c|}
\hline Order & Country & Code & $r$ & $n$ & $k$ & Probable Cause of Break \\
\hline 1 & USA & USA & 3 & 7 & 3 & \\
\hline 2 & Eurozone* & EUR & 3 & 7 & 5 & \\
\hline 3 & Japan & JAP & 6 & 7 & 5 & The real-estate/stock market crash (1992Q1) \\
\hline 4 & UK & UK & 2 & 7 & 5 & Departure from the ERM (1992Q4) \\
\hline 5 & Norway & NOR & 2 & 7 & 5 & \\
\hline 6 & Sweden & SWE & 4 & 7 & 5 & \\
\hline 7 & Switzerland & SWI & 5 & 7 & 5 & \\
\hline 8 & Canada & CAN & 4 & 7 & 5 & \\
\hline 9 & Australia & AUS & 3 & 7 & 5 & \\
\hline 10 & New Zealand & NZ & 4 & 7 & 5 & \\
\hline 11 & South Africa & SAF & 3 & 7 & 5 & \\
\hline 12 & Argentina & ARG & 5 & 7 & 5 & Effects of the Convertibility Plan (1991Q4) \\
\hline 13 & Brazil & BRA & 3 & 7 & 5 & Effects of the Real Plan (1994Q4) \\
\hline 14 & Chile & $\mathrm{CHL}$ & 4 & 7 & 5 & \\
\hline 15 & Mexico & MEX & 4 & 7 & 5 & Mexican Peso Crisis (1995Q2) \\
\hline 16 & India & IND & 3 & 7 & 5 & \\
\hline 17 & Korea & KOR & 4 & 7 & 5 & S.E. Asian crisis (1997Q4) \\
\hline 18 & Malaysia & MAL & 5 & 7 & 5 & S.E. Asian crisis (1997Q3) \\
\hline 19 & Philippines & $\mathrm{PHI}$ & 4 & 7 & 5 & S.E. Asian crisis (1997Q4) \\
\hline 20 & Singapore & SNG & 3 & 7 & 5 & \\
\hline 21 & Thailand & THA & 3 & 7 & 5 & S.E. Asian crisis (1997Q3) \\
\hline 22 & China & $\mathrm{CHN}$ & 3 & 6 & 5 & \\
\hline 23 & Indonesia & INS & 4 & 6 & 5 & S.E. Asian crisis (1997Q3) \\
\hline 24 & Peru & PER & 4 & 6 & 5 & Dollarisation; 'Washington concensus' (1994Q3) \\
\hline 25 & Turkey & TUR & 2 & 6 & 5 & \\
\hline 26 & Saudi Arabia & SAR & 4 & 5 & 5 & \\
\hline
\end{tabular}

Notes: $r, n$ and $k$ are the numbers of cointegrating vectors, endogenous variables and exogenous variables for each country/region, respectively. $(\bullet)$ is our chosen break point.

* For our purpose, the Eurozone includes Austria, Belgium, Finland, France, Germany, Italy, the Netherlands and Spain only. Eurozone data are constructed by aggregating the contributions of these member states using a PPP-GDP weighting scheme. The only exceptions are the Eurozone's export and import series, which are the total member states' exports and imports, respectively.

$\left.\Delta p_{i t}^{*}, y_{i t}^{*}\right)^{\prime}$, i.e. oil price, foreign short-term interest rate, foreign real equity price, foreign inflation and foreign real output. Lastly, as in DdPS, the US is treated as the reference country and its exchange rate is assumed to be determined in the $N$ remaining country-spedific models. Hence, the endogenous variable set of the US is $\mathrm{y}_{1 \mathrm{t}}=\left(p_{t}^{o}, r_{1 t}, i m_{1 t}, e x_{1 t}, q_{1 t}, \Delta p_{1 t}, y_{1 t}\right)^{\prime}$ while the exogenous variable set is $\mathrm{y}_{1 \mathrm{t}}^{*}=$ $\left(\tilde{e}_{1 t}^{*}, \Delta p_{1 t}^{*}, y_{1 t}^{*}\right)$. Note that $r e_{1 t}$ is exduded and $p_{t}^{o}$ induded in the set of endogenous variables for the US. Furthermore, $\tilde{e}_{i t}^{*}$ is induded among the weakly 
exogenous foreign variables, but $r_{1 t}^{*}$ and $q_{1 t}^{*}$ are excluded as they are unlikely to be weakly exogenous for the US.

Consider the following country-specific $\operatorname{VARX} *(p, p)$ model:

$$
\mathrm{y}_{\mathrm{it}}=\sum_{\mathrm{j}=1}^{\mathrm{p}} \Phi_{\mathrm{ij}} \mathrm{y}_{\mathrm{i}, \mathrm{t}-j}+\sum_{j=0}^{p} \Phi_{\mathrm{ij}}^{*} \mathrm{y}_{\mathrm{i}, \mathrm{t}-j}^{*}+\mathrm{u}_{\mathrm{it}},
$$

where $\Phi_{\mathrm{ij}}$ and $\Phi_{\mathrm{ij}}^{*}$ are, respectively, $m_{i} \times m_{i}$ and $m_{i} \times m_{i}^{*}$ coefficient matrices, and $\mathrm{u}_{\mathrm{it}} \sim \operatorname{iid}\left(0, \Sigma_{\mathrm{u}, i i}\right)$ with $\Sigma_{\mathrm{u}, i i}$ being an $m_{i} \times m_{i}$ positive definite covariance matrix. It follows that (1) can be written as

$$
\mathrm{A}_{\mathrm{i} 0} \mathrm{z}_{\mathrm{it}}=\sum_{\mathrm{j}=1}^{\mathrm{p}} \mathrm{A}_{\mathrm{ij}} \mathrm{z}_{\mathrm{i}, \mathrm{t}-j}+\mathrm{u}_{\mathrm{it}}
$$

where $\mathrm{z}_{\mathrm{it}}=\left(\mathrm{y}_{\mathrm{it}}, \mathrm{y}_{\mathrm{it}}^{*}\right)^{\prime}, \mathrm{A}_{\mathrm{i} 0}=\left(\mathrm{I}_{\mathrm{m}_{\mathrm{i}}},-\Phi_{\mathrm{i} 0}^{*}\right)$, and $\mathrm{A}_{\mathrm{ij}}=\left(\Phi_{\mathrm{ij}}, \Phi_{\mathrm{ij}}^{*}\right)$ for $j=1, \ldots, p$.

To construct the GVAR model we first define the $m \times 1$ vector of the global variables, $\mathrm{y}_{\mathrm{t}}=\left(\mathrm{y}_{1 \mathrm{t}}^{\prime}, \ldots, \mathrm{y}_{\mathrm{Nt}}^{\prime}\right)^{\prime}$ with $m=\sum_{i=1}^{N} m_{i}$. Next, we define the $\left(m_{i}+m_{i}^{*}\right) \times m$ link matrices by $\mathrm{W}_{\mathrm{i}}$, which is constructed using the average of trade-weights in the 2000s. As $z_{\mathrm{it}}$ 's can be expressed as $z_{\mathrm{it}}=\mathrm{W}_{\mathrm{i}} \mathrm{y}_{\mathrm{t}}$, we obtain the final GVAR model as follows.

$$
\mathrm{y}_{\mathrm{t}}=\sum_{j=1}^{p} \mathrm{G}_{\mathrm{j}} \mathrm{y}_{\mathrm{t}-j}+\epsilon_{\mathrm{t}},
$$

where $G_{\mathrm{j}}=\mathrm{H}_{0}^{-1} \mathrm{H}_{\mathrm{j}}, \mathrm{j}=1, \ldots, \mathrm{p}$, arean $m \times m$ matrix of GVAR coeffients, and $\varepsilon_{t}=\mathrm{H}_{0}^{-1} \mathrm{u}_{\mathrm{t}}$ with $\mathrm{H}_{\mathrm{j}}=\left(\left(\mathrm{A}_{1 \mathrm{j}} \mathrm{W}_{1}\right)^{\prime}, \ldots,\left(\mathrm{A}_{N j} \mathrm{~W}_{N}\right)^{\prime}\right)^{\prime}, j=0,1, \ldots, p$, and $\mathrm{u}_{\mathrm{t}}=\left(\mathrm{u}_{1 t}, \ldots, \mathrm{u}_{N t}^{\prime}\right)$.

As noted by PSW, global interactions can occur via three channels in the GVAR framework: (i) dependence of the country/region-specific variables, $\mathrm{y}_{i t}$ on the corresponding foreign variables, $\mathrm{y}_{\mathrm{it}}^{*}$,; (ii) dependence of the $\mathrm{y}_{i t}$ 's on global common factors; and (iii) dependence arising through non-zero contemporaneous correlations between the residuals for country $i$ and country $j$. This final point is very important when working with GCMs as they are computed on the basis of 
GFEVDs which, in turn, are computed using the global covariance matrix of $\mathrm{u}_{t}$. To see this, we may write the infinite order moving average representation of the GVAR model (3) as follows:

$$
\mathrm{y}_{t}=\sum_{j=0}^{\infty} \mathrm{B}_{j} \epsilon_{t-j},
$$

where $\mathrm{B}_{j}=\mathrm{G}_{1} \mathrm{~B}_{j-1}+\cdots+\mathrm{G}_{p-1} \mathrm{~B}_{j-p+1}, j=1,2, \ldots$, with $\mathrm{B}_{0}=\mathrm{I}_{m}$ and $\mathrm{B}_{j}=0$ for $j<0$. GFEVDs can be defined following Pesaran and Shin (1998) as:

$$
\operatorname{GFEVD}\left(y_{j t} ; u_{i t}, h\right)=\frac{\sigma_{u, i i}^{-1} \sum_{\ell=0}^{h-1}\left(\mathrm{e}_{j}^{\prime} \mathrm{B}_{\ell} \mathrm{H}_{0}^{-1} \sum_{u} \mathrm{e}_{i}\right)^{2}}{\sum_{\ell=0}^{h-1} \mathrm{e}^{\prime}{ }_{j} \mathrm{~B}_{\ell} \mathrm{H}_{0}^{-1} \mathrm{~B}_{\ell} \mathrm{e}_{j}} \text {, for } i, j=, 1 \ldots, m,
$$

where $h=1,2, \ldots, H$, is the forecast horizon and $\Sigma_{\epsilon}=\mathrm{H}_{0}^{-1} \Sigma_{\mathrm{u}} \mathrm{H}_{0}^{-1^{\prime}}$. Unlike orthogonalised FEVDs where the decomposition explains $100 \%$ of the FEV of each variable at any given horizon by construction, the sum of the GFEVDs may exceed $100 \%$ due to the non-zero correlations across shocks.

In practice, the off-diagonal blocks of the covariance matrix may be estimated imprecisely in large GVAR systems. GNS (2012b) therefore advocate a simple approach in which the global covariance matrix is restricted to be block diagonal, thereby shutting down the third channel of global interactions. Meanwhile, GNS (2013b) pursue a more datadriven approach in which the number of freely estimated covariance terms is subject to shrinkage using the weak cross-section dependence test of Pesaran (2013) at the block level. Specifically, where the null hypothesis of weak cross-section independence cannot be rejected for a given off-diagonal block at the $5 \%$ level, it is simply replaced with a null block. In practice, this approach significantly improves estimation precision.

\subsection{Generalised Connectedness Measures (GCMs)}

The first step in computing GCMs is to construct the $m \times m$ global connectedness matrix for the $m \times 1$ vector of global variables. For notational simplicity, we define 
$\phi_{j \leftarrow i}=\operatorname{GFEV} D\left(y_{j t} ; u_{i t}, h\right)$ as the variance share of $y_{i t}$ in the generalized FEV of $y_{j t}$, where we surpress the horizon index without loss of generality. Now, the global connectedness matrix may be written as follows:

$$
C=\left[\begin{array}{cccccccc}
\phi_{1 \leftarrow 1} & \cdots & \phi_{1 \leftarrow m_{1}} & \phi_{1 \leftarrow m_{1}+1} & \cdots & \phi_{1 \leftarrow m_{1}+m_{2}} & \cdots & \phi_{1 \leftarrow m} \\
\vdots & \ddots & \vdots & \vdots & & \vdots & \vdots \\
\phi_{m_{1} \leftarrow 1} & \cdots & \phi_{m_{1} \leftarrow m_{1}} & \phi_{m_{1} \leftarrow m_{1}+1} & \cdots & \phi_{m_{1} \leftarrow m_{1}+m_{2}} & \cdots & \phi_{m_{1} \leftarrow m} \\
\phi_{m_{1}+1 \leftarrow 1} & \cdots & \phi_{m_{1}+1 \leftarrow m_{1}} & \phi_{m_{1}+1 \leftarrow m_{1}+1} & \cdots & \phi_{m_{1}+1 \leftarrow m_{1}+m_{2}} & \phi_{m_{1}+1 \leftarrow m} \\
\vdots & & & & \ddots & & \vdots \\
\phi_{m_{1}+m_{2} \leftarrow 1} & \cdots & \phi_{m_{1}+m_{2} \leftarrow m_{1}} & \phi_{m_{1}+m_{2} \leftarrow m_{1}+1} & \cdots & \phi_{m_{1}+m_{2} \leftarrow m_{1}+m_{2}} & \phi_{m_{1}+m_{2} \leftarrow m} \\
\vdots & & & & & & \ddots & \vdots \\
\phi_{m \leftarrow 1} & \cdots & \phi_{m \leftarrow m_{1}} & \phi_{m \leftarrow m_{1}+1} & \cdots & \phi_{m \leftarrow m_{1}+m_{2}} & \cdots & \phi_{m \leftarrow m}
\end{array}\right]
$$

In this form, the connectedness matrix conveys a great deal of information about spillovers between the variables in the system. However, processing such a large volume of information is a daunting task given that the global connectedness matrix associated with the GNS GVAR model contains $176^{2}$ entities. We therefore follow GNS (2013b) and transform the global connectedness matrix into block form by grouping variables in an appropriate fashion and then compute GCMs using this block representation. Recall that our analysis is based on order-invariant GFEVDs so we are free to reorder the elements of (6) to be consistent with our desired block representation. As noted by GNS (2013b), grouping variables in this way introduces a new stratum in between the variable level and the systemwide aggregate level which facilitates the analysis of connectedness between countries, regions etc. while achieving a significant reduction in the output dimensionality of the model.

By selecting the relevant $E$ entities (which may be countries, regions or groups of common variables) and the associated $E^{2}$ blocks from (6), we can express $C$ as:

$$
C=\left[\begin{array}{cccc}
C_{1 \leftarrow 1}^{E} & C_{1 \leftarrow 2}^{E} & \cdots & C_{1 \leftarrow E}^{E} \\
C_{2 \leftarrow 1}^{E} & C_{2 \leftarrow 2}^{E} & \cdots & C_{2 \leftarrow E}^{E} \\
\vdots & \vdots & \ddots & \vdots \\
C_{E \leftarrow 1}^{E} & C_{E \leftarrow 2}^{E} & \cdots & C_{E \leftarrow E}^{E}
\end{array}\right]
$$


where $C_{k \leftarrow \ell}^{E}$ denotes an $m_{k} \times m_{\ell}$ matrix with $m_{k}$ and $m_{\ell}$ being the number of variables in entities $k$ and $\ell$, respectively. For example, if we define an entity, 'EU', corresponding to the Euro Area, then it would be natural to group together the 7 European variables into 'EU'. In the same way, we could define every other country as a separate entity and thereby construct a $26 \times 26$ connectedness matrix at the level of these entities. This would then permit the analysis of spillover effects between the countries in the GNS GVAR model.

GNS (2013b) note that the blocks lying on the diagonal of the entity level connectedness matrix contain all of the within-entity connectedness information. Therefore, the total within-entity variance contribution for block $k$ is given by

$$
O_{k \leftarrow k}^{E}=\mathbf{1}_{m k}^{\prime} C_{k \leftarrow k}^{E} \mathbf{1}_{m k}
$$

Where $1_{m k}$ is $m_{k} \times 1$ column vector of ones. Furthermore, $O_{k \leftarrow k}^{E}$, can be decomposed into the within-entity own-variable (denoted $O_{k \leftarrow k}^{E, O}$ ) and cross-variable FEV (denoted $O_{k \leftarrow k}^{E, S}$ ) shares as

$$
O_{k \leftarrow k}^{E}=O_{k \leftarrow k}^{E, O}+O_{k \leftarrow k}^{E, S}
$$

where $O_{k \leftarrow k}^{E, O}=\operatorname{trace}\left(C_{k \leftarrow k}^{E}\right)$ and $O_{k \leftarrow k}^{E, S}=O_{k \leftarrow k}^{E, O}$. The off-diagonal blodks in the entity-level connectedness matrix convey information about the between entity effects. The FEV contribution from entity $\ell$ to entity $k$ (called the 'from' contribution in the DY terminology) is defined as:

$$
F_{k \leftarrow \ell}^{E}=1_{m k}^{\prime} C_{k \leftarrow \ell}^{E} 1_{m \ell}
$$

while the FEV contribution to block $\ell$ from block $k$ (the 'to' contribution in DY's notation) is:

$$
T_{\ell \leftarrow k}^{E}=1_{m \ell}^{\prime} C_{\ell \leftarrow k}^{E} 1_{m k} .
$$


With this notation in hand, GNS (2013b) show that it is straightforward to derive the total from, to and net contributions for entity $\mathrm{k}$ as follows:

$$
F_{k}^{E}=\sum_{l=1, l \neq k}^{E} F_{k \leftarrow l}^{E}, T_{k}^{E}=\sum_{l=1, l \neq k}^{E} T_{l \leftarrow k}^{E}, N_{k}^{E}=T_{k}^{E}-F_{k}^{E},
$$

where $F_{k}^{E}$ measures the total between-entity FEV contributions from all other entities to entity $k, T_{k}^{E}$, measures the total between-entity FEV contributions from entity $k$ to all other entities, and $N_{k}^{E}$ is the net FEV contribution associated with entity $k$.

\subsubsection{Developing GCMs Focused on the Korean Economy}

Given our interest in the Korean economy, we can define connectedness measures which explicitly focus on within-country effects (i.e. effects which arise within Korea). Assuming that Korea is entity number 1 in the entity-level connectedness matrix (7), we can define the connectedness between real and financial variables of the Korean economy by decomposing $O_{1 \leftarrow 1}^{E}$ as

$$
O_{1 \leftarrow 1}^{E}=\left[\begin{array}{ll}
O_{1, R \leftarrow R}^{E} & F_{1, R \leftarrow F}^{E} \\
F_{1, F \leftarrow R}^{E} & O_{1, F \leftarrow F}^{E}
\end{array}\right] .
$$

where $O_{1, R \leftarrow R}^{E}\left(O_{1, F \leftarrow F}^{E}\right)$ denotes the contribution of real (financial) variable group to its own $h$-step ahead FEV. Similarly, $F_{1, R \leftarrow F}^{E}\left(F_{1, F \leftarrow R}^{E}\right)$ represents the cross-contribution of the financial (real) variables to the h-step ahead FEV of real (financial) variables in Korea. By extension, we can apply a similar real/financial decomposition to the remaining entities in (6) without difficulty.

To further investigate the connectedness between the seven domestic endogenous variables for Korea in the GNS GVAR model, we can further decompose $O_{1 \leftarrow 1}^{E}$ into 


$$
O_{1 \leftarrow 1}^{E}=\left[\begin{array}{cccc}
O_{1,1 \leftarrow 1}^{E} & F_{1,1 \leftarrow 2}^{E} & \cdots & F_{1,1 \leftarrow 7}^{E} \\
F_{1,2 \leftarrow 1}^{E} & O_{1,2 \leftarrow 2}^{E} & \cdots & F_{1,2 \leftarrow 7}^{E} \\
\vdots & \vdots & \ddots & \vdots \\
F_{1,7 \leftarrow 1}^{E} & F_{1,7 \leftarrow 2}^{E} & \cdots & O_{1,7 \leftarrow 7}^{E}
\end{array}\right]
$$

where $O_{1, j \leftarrow j}^{E}$ denotes the within-entity own-variable FEV contribution for variable $j$ and $F_{1, j \leftarrow i}^{E}\left(F_{1, i \leftarrow j}^{E}\right)$ represents the FEV contribution from the $i$ th variable to the $j$ th variable at the $h$-step ahead horizon. 


\section{Empirical Results}

Our empirical analysis proceeds in two stages. First, we evaluate the average connectedness between the Korean economy and the global economies over the pre-crisis period 1980q2-2007q2. Having established a reference point, we then investigate the changes in the nature and extent of connectedness brought about during the GFC by means of recursive estimation over the samples 1980q2-2005q2 to 1980 q2-2012q3.

\subsection{Pre-Crisis Average Connectedness, 1980-2007}

\subsubsection{Aggregate Connectedness}

Figure 2 plots the aggregate connectedness measures of the Korean economy. We find that, on average, the own FEV contribution (the sum of within-country own-variable and cross-variable FEV shares) is initially considerable but rapidly falls as the horizon increases, mainly due to reductions in the own variable FEV share. The proportion of the Korean FEV explained by other countries is very considerable even at $\mathrm{h}=0$, and it gradually rises to reach a plateau after 8 quarters. The to-contribution, which measures the extent to which Korea influences the rest of the world, is always smaller than the from-contribution, resulting in a negative net effect, indicating that Korea is susceptible to foreign conditions to a greater degree than it affects them. This is consistent with the characterisation of Korea as a small open economy with a heavily export-oriented structure, extensive reliance on imported energy and an open capital market. Overall, we find that domestic and foreign factors exert a comparable influence on the Korean economy in the very short run but that foreign influence rapidly comes to dominate at the longer horizons. This indicates that the stability of the Korean economy is dependent to some degree on the actions of supranational bodies, particularly in the longer term. This is consistent with the pattern of global connectedness documented in GNS (2013b). 
Figure 2: Aggregate Connectedness Measures of Korea
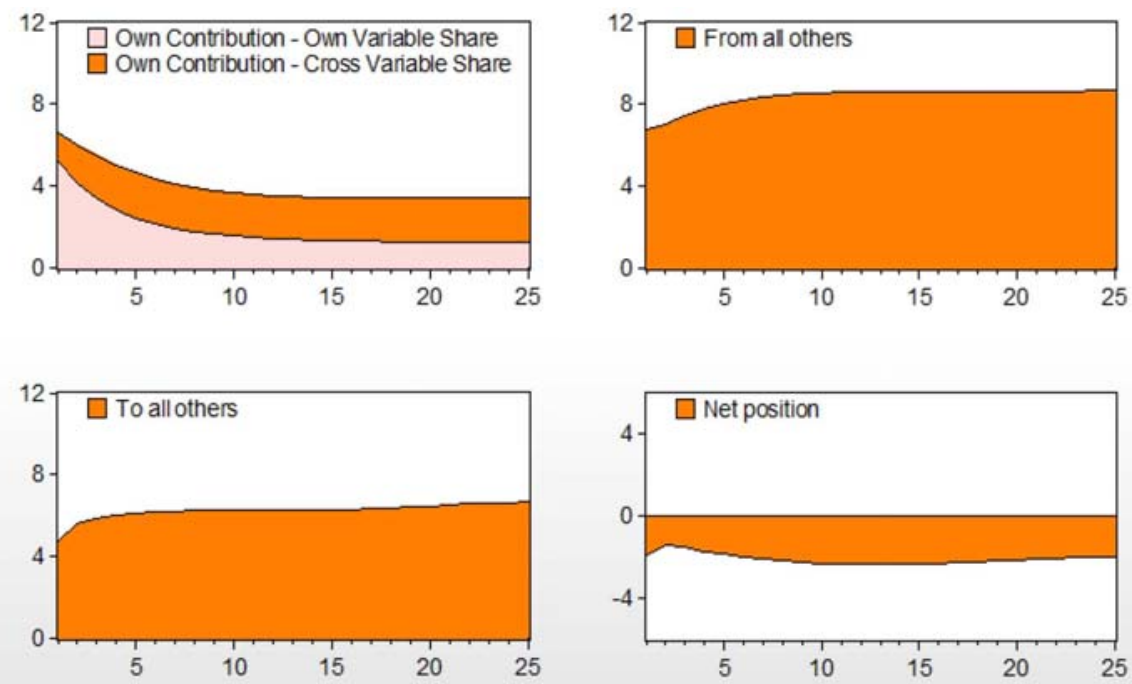

Notes: Aggregate connectedness of Korea with all the other countries. The sample period is 1980Q2-2007Q2.

\subsubsection{Aggregate Connectedness with Real-Financial Decomposition}

To examine how the real and financial sectors of the Korean economy are connected with those of the rest of the world, we construct two variables groups: 'real' and 'financial'. Figure 3 presents connectedness measures in light of this real-financial dichotomy. The own FEV contributions of both the real and financial sectors are initially considerable. The own contribution of the real sector then dedines gradually with the horizon while that of the financial sector drops only slightly. Domestic cross-contributions between the financial and real sectors are considerably smaller than their respective own contributions, with the spillover from financial to real variables being somewhat stronger than that from real to financial variables in the short term. This is likely to be related to the fact that financial magnitudes react to shocks much faster than real magnitudes.

The contributions to the FEV s of the Korean financial and real sectors coming from shocks in the rest of the world increase gradually. The effect of foreign financial variables is dearly dominant ats all horizons, indicating that Korea is 
Figure 3: Decomposition of Aggregate Connectedness Measures of Korea
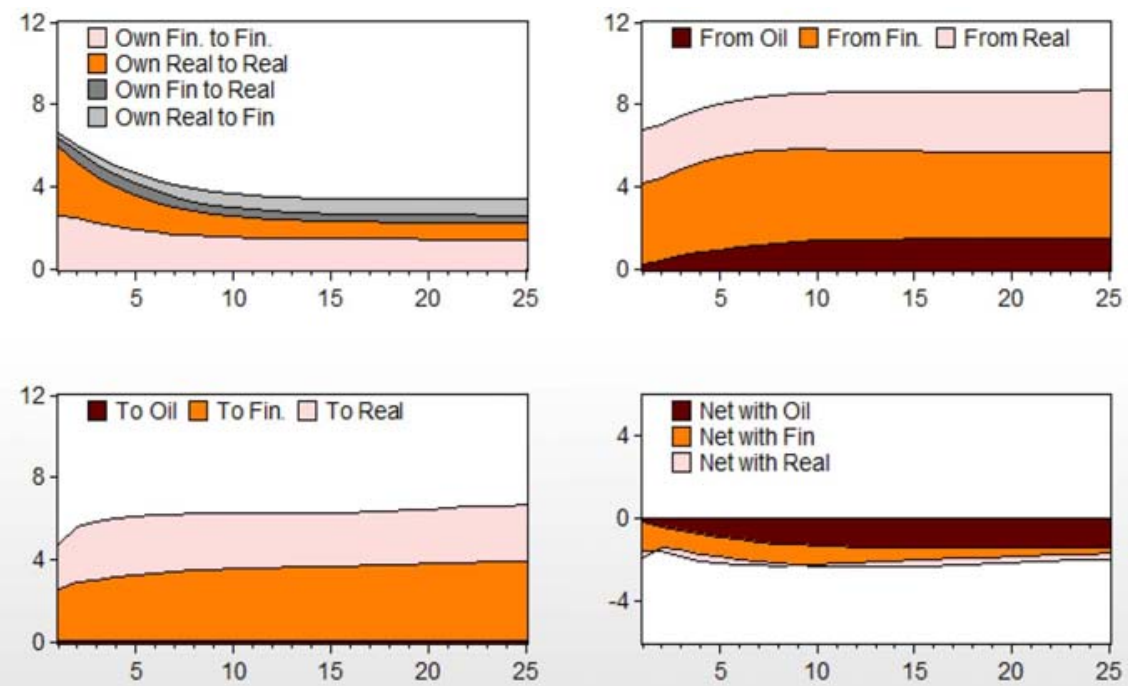

Notes: Decomposition of Aggregate connectedness of Korea with all the other countries. Variables include real effective exchange rate $(r e)$, interest rate $(r)$, stock market $\operatorname{index}(q)$, inflation $(\pi)$, inflation $(i m)$, exports $(e x)$, and real output $(y)$.

vulnerable to shocks emanating from the world's major financial centres as well as its key trading partners. Meanwhile, the effect of overseas real shocks is also non-negligible, presumably reflecting the importance of overseas demand for Korean goods. Finally, the influence of the oil price on the Korean economy is initially negligible but builds across horizons, suggesting that Korea's reliance on energy imports leaves the economy exposed to volatility in energy prices.

The to-between contributions going out from Korea to the rest of the world are equally divided between the foreign financial and real sectors, with Korean shocks exerting almost no effect whatsoever on the oil price. We find that the net position is roughly balanced in terms of real sector transmission at all horizons but this cannot be said of either the financial sector or oil, where Korea is a net receiver of shocks in both cases. Interestingly, we find that the Korean economy is affected mostly by overseas financial conditions in the short term but it becomes more susceptible to oil price fluctuations in the long run, a result which has obvious implications for domestic macroeconomic management. 


\subsubsection{Connectedness of Domestic I ndividual Variables}

Figure 4 reports a stylised summary of GFEVDs for each of the seven Korean domestic variables. In each case GFEVDs are decomposed into five components as follows: own (the proportion of the variable's FEV explained by the variable itself), other dom (the proportion explained by the remaining domestic variables), oil (the proportion explained by the oil price), usstock (the proportion explained by the US stock price), and other_foreign (the proportion explained by all foreign variables exduding oil and us stock prices).

A number of stylised patterns emerge. The own contribution is dominant in the short horizon but its importance falls rapidly as the horizon rises. The combined contributions of oil price, the US stock price and other foreign variables increase markedly with the horizon in all cases except the interest rate and the real exchange rate. The contribution of the oil price becomes very large in the case of real exports, equity prices and real output, but plays a much less prevalent role in the remaining cases. On the other hand, the contribution of the US equity price becomes substantial in the case of interest rates, equity prices, real exports, real imports and inflation.

We now examine the raw GFEVDs to place these connectedness measures in context.

The real exchange rate The own contribution starts at $12.5 \%$ before gradually diminishing to $8.2 \%$ after 12 quarters. The total contribution of the other domestic variables increases from $4.5 \%$ to $10.6 \%$, with the most significant contributions from the stock market, the interest rate and exports. The contribution of the oil price is almost muted, averaging just $1.26 \%$ over 12 quarters. The contribution of the US stock price is almost negligible. The remainder (more than $80 \%$ on average) is accounted for by overseas conditions in Korea's trading partners. This is an intuitively pleasing finding for a small, open and export-oriented economy such as Korea. J apanese exchange rates are significant contributors in the shorter horizons, being supplanted by Chinese imports, EU exchange rates and the US output in the longer horizons.

The interest rate The own contribution decreases sharply from $46.6 \%$ to $8.6 \%$ after 12 quarters. The contribution of other domestic variables rises from $5.8 \%$ to 
Figure 4: Stylised Summary of GFEVDs for each of the Korean Domestic Variables

(a) The real exchange rate

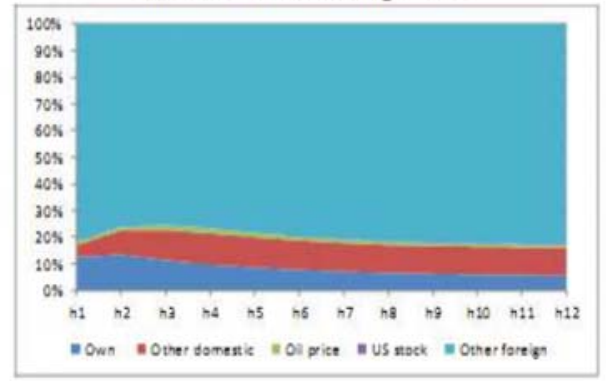

(c) The equity prices

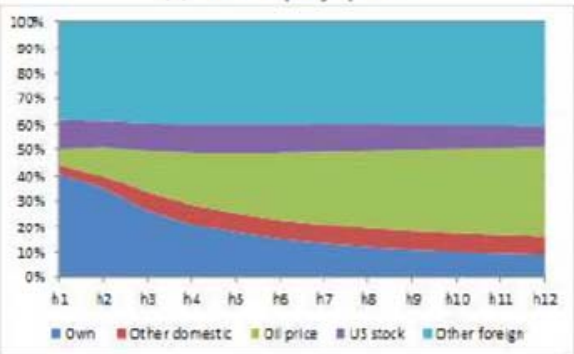

(e) Real imports

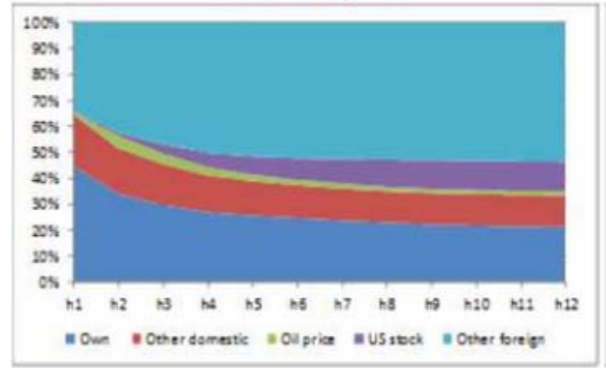

(g) Real output

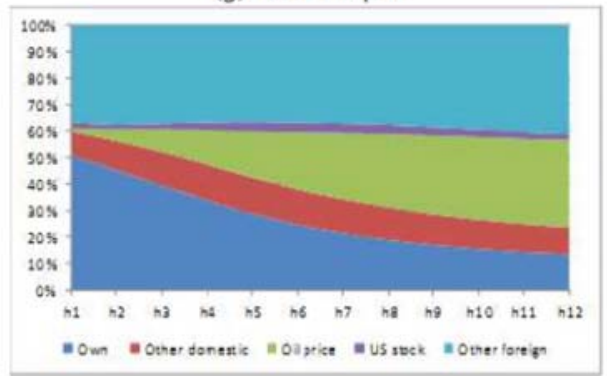

(b) The interest rates

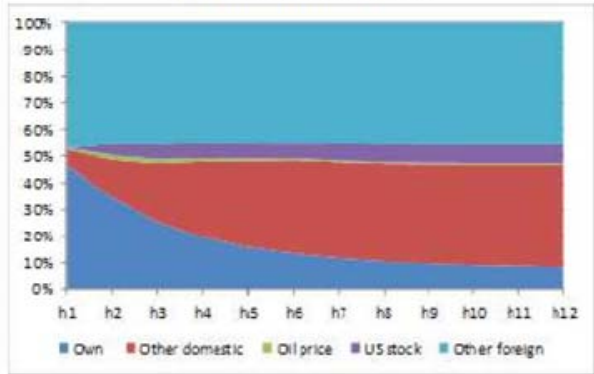

(d) Real exports

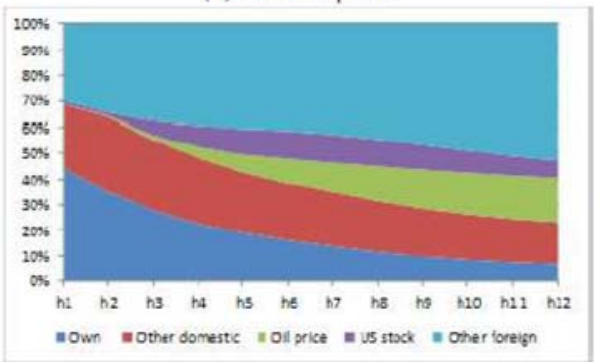

(f) Inflation

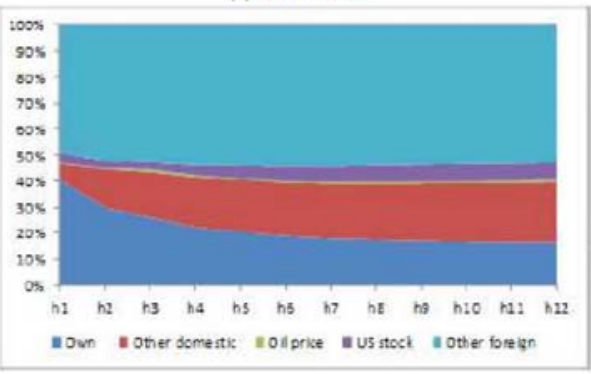


$38.2 \%$ The total domestic contribution remains remarkably stable at roughly $48 \%$ Oil price plays a peripheral role while the contribution of the US stock price jumps from $0 \%$ at 1 quarter to over $7 \%$ after 12 quarters. The contribution of other foreign variables also remains at around $45 \%$. The most important foreign contributors are the US and European stock markets and Chinese inflation, each of which influences Korean inflation. A plausible explanation of this finding is that the Korean monetary policy tends to focus on both domestic and foreign focus, simultaneously.

The equity prices The own contribution dedines substantially from $41 \%$ to $9 \%$ while the contribution of the other domestic variables remains relatively small, averaging $6.7 \%$ over the 12 quarter horizon. This suggests that domestic economic conditions do not exert a dominant influence on the performance of the KOSPI which reflects the index's rapid integration into the global financial system, especially after the IMF bailout in 1997-8. The contribution of the oil price is significant, starting at $6.1 \%$ and reaching $34.8 \%$. This reflects the considerable energy intensity of economic activity coupled with its reliance on imported oils. The contribution of the US equity prices peaks immediately at $11.6 \%$ and gradually dedines to $8.6 \%$ The contribution of other foreign variables (induding the US stock prices) is substantial and remarkably stable at 50\% EU and J apanese equity prices also play a non-negligible role. This evidence suggests that the KOSPI is relatively insensitive to domestic conditions ( $25 \%$ on average) but it is highly sensitive to overseas conditions.

Real exports We observe a significant own contribution of $45 \%$ at 1 quarter horizon. This diminishes rapidly to $7 \%$ after 12 quarters. The contribution of the other domestic variables are $24 \%$ and $16.2 \%$, respectively. The contribution of the oil price is negligible at shorter horizons, but jumps to $17.5 \%$ after 12 quarters. The contribution of the US equity prices starts from just 1.2\% after 1 quarter, peaks at $11 \%$ after 6 quarters and settles at $7 \%$ after 12 quarters. The contribution of other foreign variables increases from $30 \%$ to $53 \%$, the majority of which are accounted for by the US macroeconomic variables (equity prices, output and prices).

Real imports We also observe a significant own contribution at 1 quarter 
horizon of $45 \%$ This falls to $21 \%$ after 12 quarters. The contribution of the remaining domestic variables are $20 \%$ and $12 \%$, respectively. The most important domestic variable is inflation while for exports it is the real exchange rate. These results highlight an importance of the relative purchasing power concern. At shorter horizons, the contributions of the oil price and the US equity prices are negligible. The former remains fairly small at $2.3 \%$ on average whereas the contribution of US equity prices jumps to $11.2 \%$ after 12 quarters. Government intervention in energy markets may explain the relatively muted effect of the oil price on imports. Meanwhile, the contribution of other foreign variables increases from $35 \%$ to $54 \%$ with the most important contributors being US output and prices, Chinese output and European equity prices.

Inflation The own contribution falls sharply from $40.5 \%$ to $16.5 \%$ while the contribution of the other domestic variables grows from $6 \%$ to $23 \%$. Real imports are the most significant domestic variables contributing $16 \%$ on average, suggesting that it renders the task of domestic macroeconomic management considerably complicated. The contribution of the oil price is negligible $(0.7 \%$ on average). The contribution of the US equity prices rises smoothly from $3.9 \%$ to $6.4 \%$ Other foreign contribution is large, and rises from $49 \%$ to $54 \%$ with the most important variables being US output, Chinese inflation, the US price level, and EU output.

Real output We observe the familiar dedine in the own contribution as the horizon rises (50\% to $13 \%$ ). The contribution of other domestic variables remains fairly constant between $9 \%$ and $13 \%$ The contribution of oil price is considerable especially in the long-term, reaching 33\% after 12 quarters. The contribution of the US equity prices is rather muted and stable at $2.8 \%$ on average. Other foreign contribution is immediate and substantial, growing from $37 \%$ to $42 \%$, with the most important variables being the US price level, and real imports. This reflects the dominant position of the US among Korea's trading partners.

Table 2 provides the summary of the key three variables that account for the largest proportion of the FEV for each of the Korean domestic variables. The principle factors affecting the Korean economy are domestic conditions as well as financial conditions in the US and the European real exchange rate. When 
Table 2: Main Contributors to GFEVDs of Korean Variables.

\begin{tabular}{|c|c|c|c|c|c|c|c|}
\hline Horiz & re & $r$ & $i m$ & $e x$ & $q$ & $\pi$ & $y$ \\
\hline & $\begin{array}{l}\text { KOR re }(13 \%) \\
\text { JAP re }(10 \%) \\
\text { JAP im }(8 \%)\end{array}$ & $\begin{array}{l}\text { KOR } r(47 \%) \\
\text { PER } \pi(7 \%) \\
\text { KOR re }(4 \%)\end{array}$ & $\begin{array}{l}\text { KOR im }(45 \%) \\
\text { KOR ex }(8 \%) \\
\text { KOR } y(7 \%)\end{array}$ & $\begin{array}{l}\text { KOR ex }(45 \%) \\
\text { KOR re }(11 \%) \\
\text { KOR im }(10 \%)\end{array}$ & $\begin{array}{l}\text { KOR } q(41 \%) \\
\text { US } q(12 \%) \\
\text { US po }(6 \%)\end{array}$ & $\begin{array}{l}\text { KOR } \pi(40 \%) \\
\text { KOR } i m(5 \%) \\
\text { US } q(4 \%)\end{array}$ & $\begin{array}{l}\text { KOR y }(51 \%) \\
\text { KOR im }(7 \%) \\
\text { SWE re }(5 \%)\end{array}$ \\
\hline & $\begin{array}{l}\text { KOR re }(1 \%) \\
\text { KOR } q(6 \%) \\
\text { JAP re }(5 \%)\end{array}$ & $\begin{array}{l}\text { KOR } r(20 \%) \\
\text { KOR re }(11 \%) \\
\text { KOR } q(6 \%)\end{array}$ & $\begin{array}{l}\text { KOR im }(27 \%) \\
\text { US } q(6 \%) \\
\text { KOR } \pi(5 \%)\end{array}$ & $\begin{array}{l}\text { KOR ex }(23 \%) \\
\text { KOR re }(13 \%) \\
\text { US } q(8 \%)\end{array}$ & $\begin{array}{l}\text { KOR } q(21 \%) \\
\text { US po }(20 \%) \\
\text { US } q(11 \%)\end{array}$ & $\begin{array}{l}\text { KOR } \pi(22 \%) \\
\text { KOR } i m(15 \%) \\
\text { EU } y(4 \%)\end{array}$ & $\begin{array}{l}\text { KOR y }(34 \%) \\
\text { US po }(13 \%) \\
\text { KOR im }(7 \%)\end{array}$ \\
\hline & $\begin{array}{l}\text { KOR re }(7 \%) \\
\text { KOR } q(6 \%) \\
\text { EU re }(5 \%)\end{array}$ & $\begin{array}{l}\text { KOR re }(12 \%) \\
\text { KOR } r(11 \%) \\
\text { KOR } q(9 \%)\end{array}$ & $\begin{array}{l}\text { KOR im }(23 \%) \\
\text { US } q(10 \%) \\
\text { KOR } \pi \quad(6 \%)\end{array}$ & $\begin{array}{l}\text { US po }(14 \%) \\
\text { KOR ex }(12 \%) \\
\text { US } q(10 \%)\end{array}$ & $\begin{array}{l}\text { US po }(30 \%) \\
\text { KOR } q(12 \%) \\
\text { US } q(11 \%)\end{array}$ & $\begin{array}{l}\text { KOR } i m(19 \%) \\
\text { KOR } \pi \quad(18 \%) \\
\text { US } q(6 \%)\end{array}$ & $\begin{array}{l}\text { US po }(28 \%) \\
\text { KOR } y(19 \%) \\
\text { US } \pi(6 \%)\end{array}$ \\
\hline$h=12$ & $\begin{array}{l}\text { KOR re }(6 \%) \\
\text { KOR } q(5 \%) \\
\text { CHN im }(5 \%)\end{array}$ & $\begin{array}{l}\text { KOR re }(13 \%) \\
\text { KOR } q(10 \%) \\
\text { KOR } r(9 \%)\end{array}$ & $\begin{array}{l}\text { KOR im }(21 \%) \\
\text { US } q(11 \%) \\
\text { KOR } \pi(8 \%)\end{array}$ & $\begin{array}{l}\text { US po }(17 \%) \\
\text { KOR ex }(7 \%) \\
\text { US } q(7 \%)\end{array}$ & $\begin{array}{l}\text { US po }(35 \%) \\
\text { KOR } q(9 \%) \\
\text { US } q(9 \%)\end{array}$ & $\begin{array}{l}\text { KOR im }(21 \%) \\
\text { KOR } \pi(17 \%) \\
\text { US } q(6 \%)\end{array}$ & $\begin{array}{l}\text { US po }(33 \%) \\
\text { KOR } y(13 \%) \\
\text { US } \pi(5 \%)\end{array}$ \\
\hline Average & $\begin{array}{l}\text { KOR re }(8 \%) \\
\text { KOR } q(5 \%) \\
\text { JAP re }(4 \%)\end{array}$ & $\begin{array}{l}\text { KOR } r(18 \%) \\
\text { KOR } r e(11 \%) \\
\text { KOR } q(7 \%)\end{array}$ & $\begin{array}{l}\text { KOR im }(27 \%) \\
\text { US } q(8 \%) \\
\text { KOR } \pi(6 \%)\end{array}$ & $\begin{array}{l}\text { KOR ex }(19 \%) \\
\text { US po }(9 \%) \\
\text { KOR re }(9 \%)\end{array}$ & $\begin{array}{l}\text { US po }(25 \%) \\
\text { KOR } q(18 \%) \\
\text { US } q(10 \%)\end{array}$ & $\begin{array}{l}\text { KOR } \pi(22 \%) \\
\text { KOR } i m(16 \%) \\
\text { US } q(5 \%)\end{array}$ & $\begin{array}{l}\text { KOR y }(27 \%) \\
\text { US po }(2 \%) \\
\text { KOR im }(6 \%)\end{array}$ \\
\hline
\end{tabular}

Notes: The contributions in this table have been normalized such that the total GFEVD of each variable sum to $100 \%$ at each horizon. Average is the average of the contributions in the first 12 forecast horizons. Variables include real effective exchange rate $(r e)$, interest rate $(r)$, stock market index $(q)$, inflation $(\pi)$, import $(i m)$, export $(e x)$, real output $(y)$, and oil price $(p o)$.

broadening the analysis to consider the top ten contributors rather than the top 3 (results are not reported here but available on request) we find that they typically account for between $70 \%$ and $90 \%$ of the total FEV and that the most heavily represented nations are Korea, the US, the Eurozone, China and Japan, as expected. Finally, when comparing the current estimation results with those reported in GNS (2012b) which are obtained on the basis of the block diagonal covariance matrix of the global shocks, ut, overall, we find that both results are qualitatively similar. However, a further inspection dearly suggests that the current results obtained after applying the formal CDS testing procedure seem to provide more plausible findings. In particular, we now document evidence that foreign contributions are more substantial in explaining the FEV's of exchange rates and interest rates.

\subsubsection{Regional Connectedness}

We now consider the connectedness of the Korean economy with the following ten regions: the US, the EU, Japan, the UK, BIC (Brazil, India and China), 
OEURO (other European countries: Norway, Sweden and Switzerland), OCEANA (Australia and New Zealand), ASEAN (Singapore, Thailand, Malaysia, Philippines and I ndonesia), Latin America (Argentina, Chile, Mexico and Peru), ROW (the rest of the world: Canada, South Africa, Turkey and Saudi Arabia). Figure 5 reports the results, with panel (a) showing the from-contributions from the world economy to Korea and panel (b) showing the to-contributions from Korea to the world. We observe the familiar dedine in the own domestic contribution as the horizon rises (from $49 \%$ to just 29\%).

Focusing initially on panel (a), we find that the dominant contributors to conditions in the Korean economy are the US, ASEAN and the oil price, although the roles of the EU, the BICs and the other European countries are non-negligible at $5-7 \%$ Interestingly, we find that J apanese contribution is significant at the 1 quarter horizon (6\%), but dedines smoothly to a mere $2 \%$ after 12 quarters. On the other hand, the combined contributions of the US and the oil price increase markedly with the horizon (from $5 \%$ to $26 \%$ ).

Moving on to pane (b), we find that the largest to-between contributions are associated with the ASEAN and other European countries, although the Korean contributions to the EU, the BICS and OCEANA are also non-negligible. Interestingly, the Korean contribution to the Japanese economy is initially small, but it gradually rises in the longer horizons. Meanwhile, Korea's influences on the US economy and on the oil price are almost entirely negligible at all forecast horizons as one would expect.

Overall, these results are consistent with the recent trend that the trade shares of both China and ROW (especially, ASEAN) have been on the rise whilst the shares of the historically important trading partners such the US, the EU and Japan have steadily dedined. Clearly, this reflects that the international trading structure of Korea has been gradually and steadily diversified, which helps to reduce the volatility of exports and imports and thus enhance stability of the Korean economy. This suggests that the policymaker in Korea should now pay more attention to the probability of the crisis stemming from emerging economies, in order to avoid their potentially devastating contagious impacts especially through real connectedness. 
Figure 5: FROM and TO Contributions of Korea with 10 Regions and the Oil price

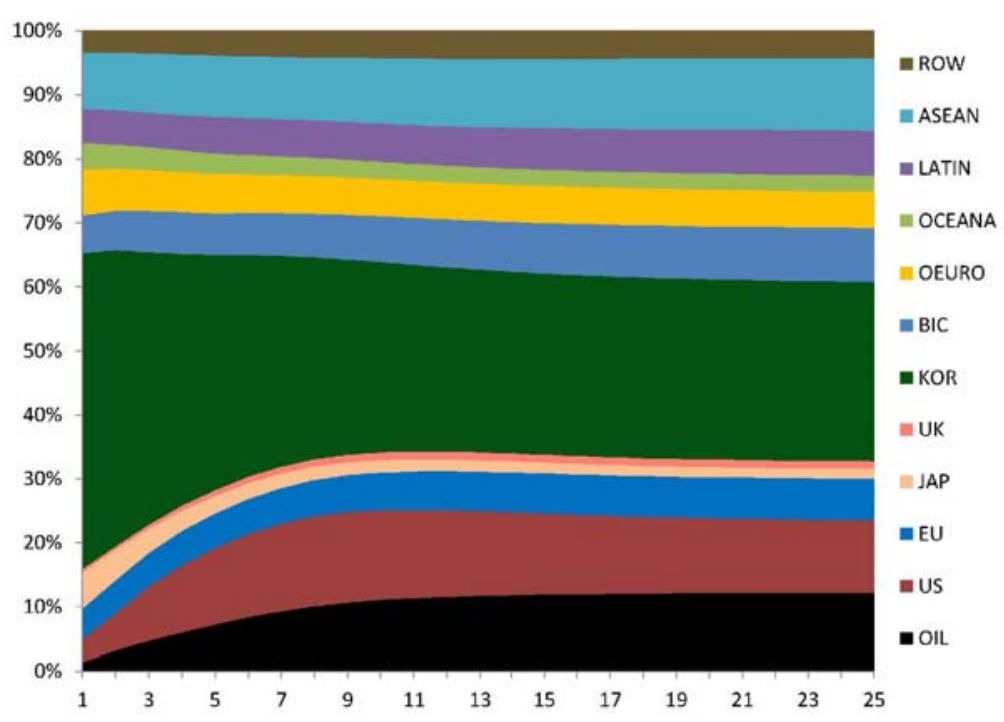

(a) FROM contributions of KOR

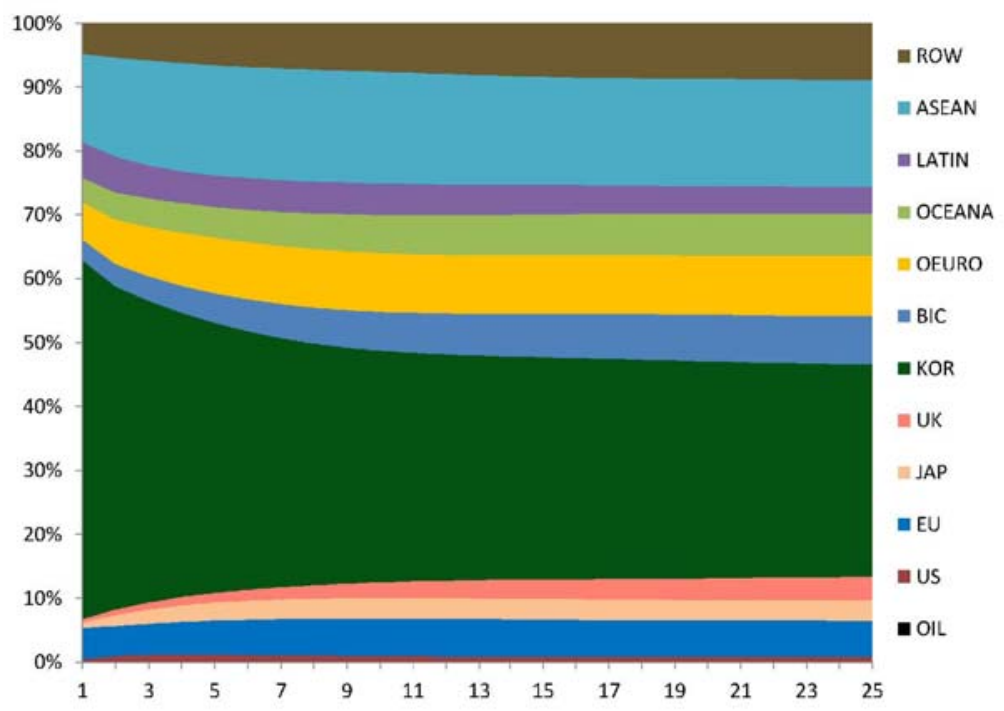

(b) TO contributions of KOR

Notes: The other 10 regions (US, EU, JAP, UK, BIC (Brazil, India, China), OEURO (other European countries: Norway, Sweden, Switzerland), OCEANA (Australia, New Zealand), ASEAN (Singapore, Thailand, Malaysia, Philippines, Indonesia), Latin America (Argentina, Chile, Mexico, Peru), ROW (rest of the world: Canada, South Africa, Turkey, Saudi Arabia)) and the oil price. 


\subsubsection{Regional Connectedness with Real-Finandial Decomposition}

Figure 6 reports the connectedness analysis by further decomposing real and financial sectors. Panels (a) and (b) provide the from-contributions of the Korean real and financial variables. We also observe the familiar dedines in the own contributions as the horizon rises, especially for real sector (48\% to $20 \%$ ). The most dominant contributors to the Korean financial sector are found to be financial variables of ROW and the US, real variables of Korea and ROW, and the oil price, although the roles of the financial sector of the EU and of real sectors of the US, the EU and China are non-negligible Interestingly, Japanese contribution is relatively muted except for the shorter horizons. From Panel (b) we find that the largest from-contributions are associated with financial variables of ROW and the oil price, followed by financial variables of the US and Korea as well as real variables of ROW. Further, the roles of real variables of Korea, the US, the EU and China are non-negligible. Interestingly, we find that the combined longer-term contributions of the US financial sector and the oil price to the Korean real sector are found to be much stronger than those for the Korean financial sector ( $24 \%$ vs $12 \%)$, although their short-term contributions are immediate for the Korean financial sector.

Panels (c) and (d) of Figure 6 present the to-contributions of the Korean financial and real variables to the world. The largest to-contributions of the Korean financial variables are associated with finandial sectors of ROW and Korea, followed by real sectors of ROW and Korea, which account for more than $90 \%$ across all horizons. Next, we find that the largest to-contributions of the Korean real sectors are confined mostly to financial and real variables of Korea and ROW (accounting for about 90\%). On the other hand, as expected, the contributions of both financial and real sectors in Korea to the four focus countries have been quite small at $10 \%$ or less.

A few more comments are in older. Notice, currently, that the Korean investment shares of the US and the EU financial assets still account more than $50 \%$ for both equities and bonds. After the GFC, however, Korea has attempted to diversify its foreign investments by increasing the investment share of the EU 


\section{Figure 6: FROM and TO Contributions of Korean Financial and Real Variables}

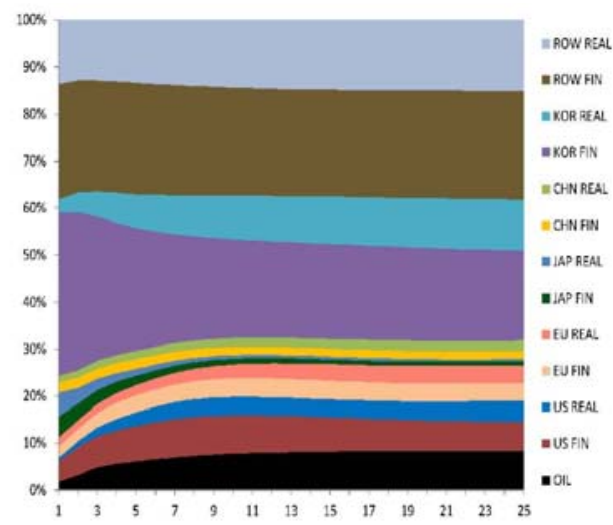

(a) FROM contributions of KOR Financial Var.

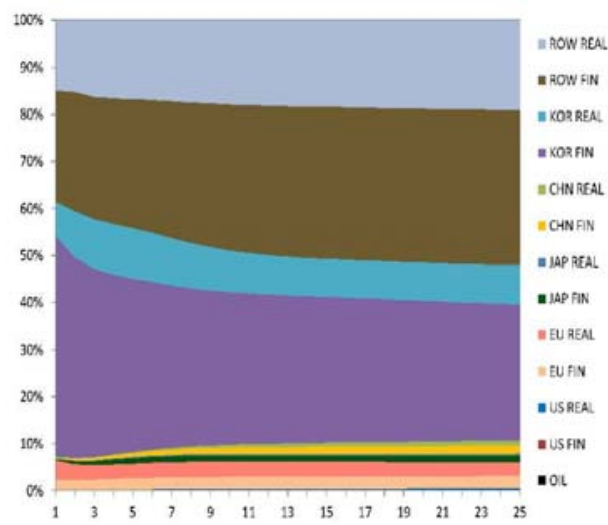

(c) TO contributions of KOR Financial Var.

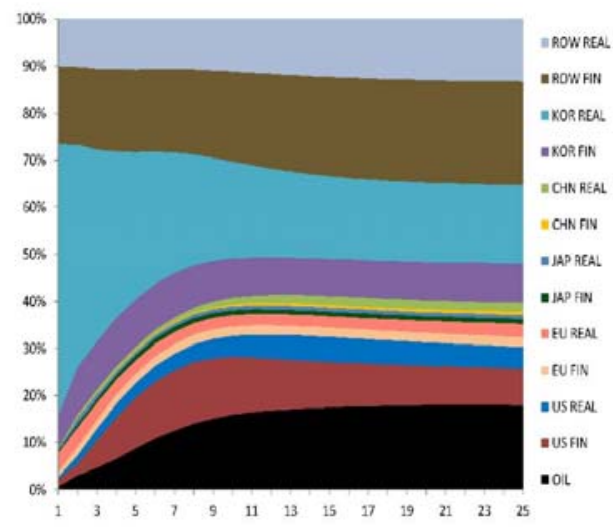

(b) FROM contributions of KOR Real Var.

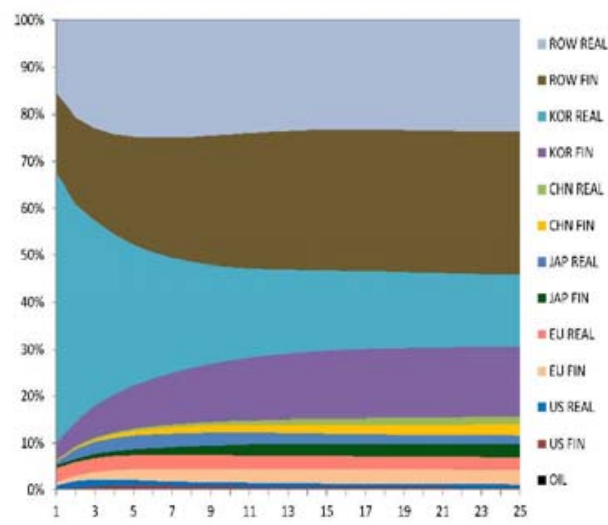

(d) TO contributions of KOR Real Var.

Notes: Decomposition of FROM and TO contributions between Korea and the US, EU, Japan, China, Rest of the World (ROW: all other countries), and oil price into financial and real contributions. Variables include real effective exchange rate $(r e)$, interest rate $(r)$, stock market index $(q)$, inflation $(\pi)$, import $(\mathrm{im})$, export $(e x)$, and real output $(y)$.

bonds and decreasing the share of the US bonds, simultaneously. Turning to the foreign investments of the Korean financial assets, we note that the US and the EU are still dominant investors in the Korean stock market, and their combined shares account more than $80 \%$ of the total foreign investments. On the other hand, the EU investment share of for the Korean bonds has significantly dedined while the 
share of the ROW has significantly risen. This dearly reflects the recent trend that the central banks of ASEAN countries have increased their investment shares of the Korean government bonds (regarded as one of most safe assets in emerging economies) for the purpose of their portfolio diversification. These findings on the real connectedness channel are mostly pleasing as the oil price hike tends to deteriorate the terms of trade, leading to the fall of exports and the slowdown of growths. Furthermore, provided that the oil price hikes have resulted mainly from excess demand of the global economy, it follows that oil price changes should have a very tight relationship with the equity price changes. The finding that the contribution of the oil price to inflation is negligible ( $0.7 \%$ on average), suggests that government intervention in energy market seems to have succesfully limited the degree to which fluctuations in energy prices are passed through to the Korean inflation. For Korea with an open capital market, the propagation of the shocks from global financial markets has become more immediate and complex. In particular, the Korean stock market has become more strongly synchronised with the US market. As of 2012, the US investment share is nearly the half (47.2\%). Asa result, the domestic investors tend to display the herding behavior, chasing the US investors. As the US equity index can be regarded as a barometer of the US economic outlook, it is not surprising to find that the connectedness of Korean exports and imports is substantial with the US equity price.

\subsubsection{Mapping Korea's Bilateral Connectedness}

Further, we follow GNS (2013b) and develop the global risk maps which can display the geographical element of our connectedness results. Notice that these figures are constructed differently from those in GNS (2013b) who plot the aggregate net transmission ratios of an individual country associated with the rest of the world. Here, from the Korean perspective, we define the bilateral net transmission ratios associated with any individual country or region as follows:

$$
N_{i}^{K O R}=\frac{T_{K O R \rightarrow i}-F_{K O R \leftarrow i}}{T_{K O R \rightarrow i}+F_{K O R \leftarrow i}},
$$


where $T_{K O R \rightarrow i}$ denotes the to-between contribution from Korea to country $i, F_{K O R \leftarrow i}$ denotes the from-between contribution from country $i$ to Korea. By construction this ratio ranges between -1 and 1 . A negative (positive) ratio indicates that Korea is the (bilateral) net shock receiver (transmitter) while a zero ratio indicates that Korea is neither a shock-receiver nor a shock-transmitter. By overlaying these measures onto a world map, we can identify hot spots for the transmission of shocks to the Korean economy.

Figure 7 presents the shock transmission maps at 1, 2, 4 and 8 quarter ahead horizons. It is dear across all four figures that the dominant shock transmitters to the Korean economy are the US and the oil price. Furthermore, the transmission ratio increases through time for the US and the oil price, indicating that they are the most important external driver of the Korean economy. China and Brazil also transmit shocks within the Korean economy, but not as strongly. Japan transmit shocks to the Korean economy strongly in the short run only, but its influence is not long-lasting and fades quickly after 2 quarters. Interestingly, however, the bilateral net position of Korea with the Eurozone is more or less neutral across all forecast horizons, indicating that the EU cannot be considered quite as a strong driver of the Korean economy. The remainder of the economies are either neutral or net receivers. This stylised representation provides a simple means of assessing the risks to the Korean economy posed by an individual country-specific or global shocks. As the US is such a strong transmitter, it is not surprising to observe that the effects of the GFC were passed through to the Korean economy rapidly and strongly. Similarly, several oil price shocks have had considerable impacts. Therefore, economic instability in the US and shocks occurring in major oil producing regions should be of most concerns to the Korean economic policy-maker. On the other hand, our results indicate that shocks within the Eurozone are not likely to be strongly transmitted to the Korean economy. This is quite different from GNS (2013b) who document evidence that any traumatic shocks within the Eurozone are likely to prove very damaging to global prosperity. Finally, the importance of China as a shock transmitter is likely to increase dramatically with its growing prominence in the global economy. 
Figure 7: Bilateral From-Transmission Ratios of Korea with All Others

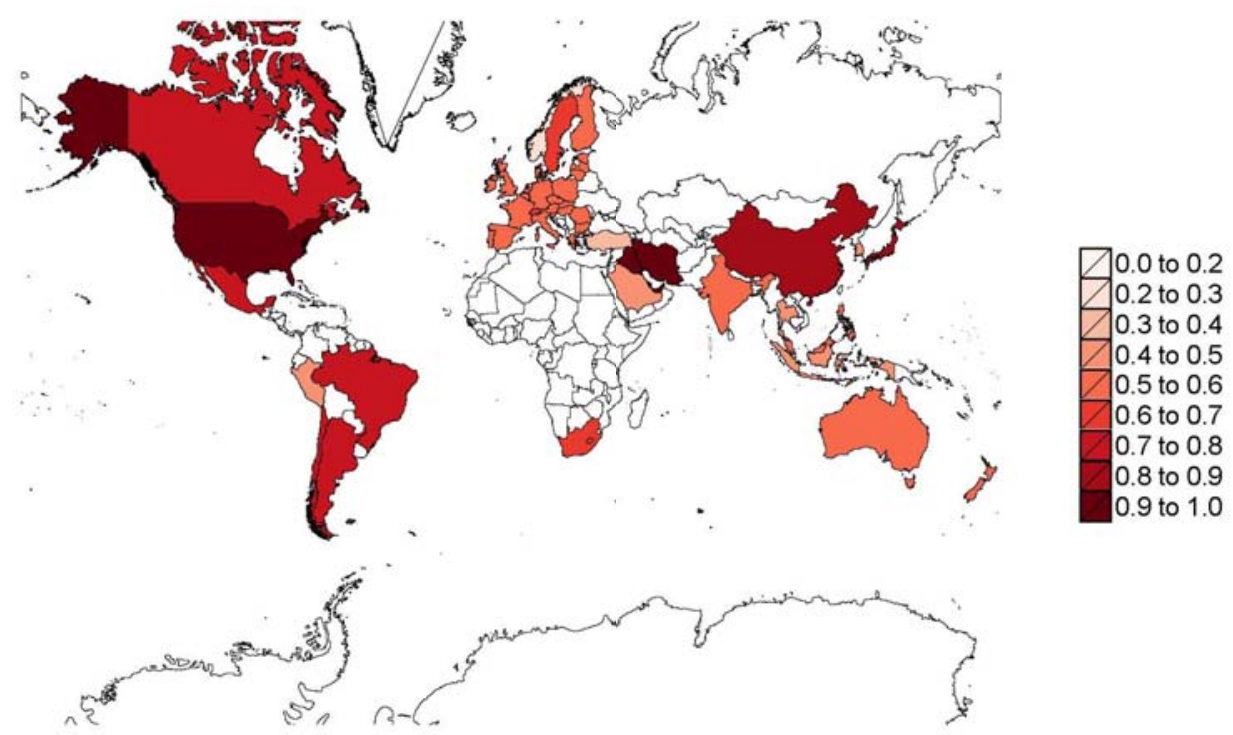

(a) $h=1$
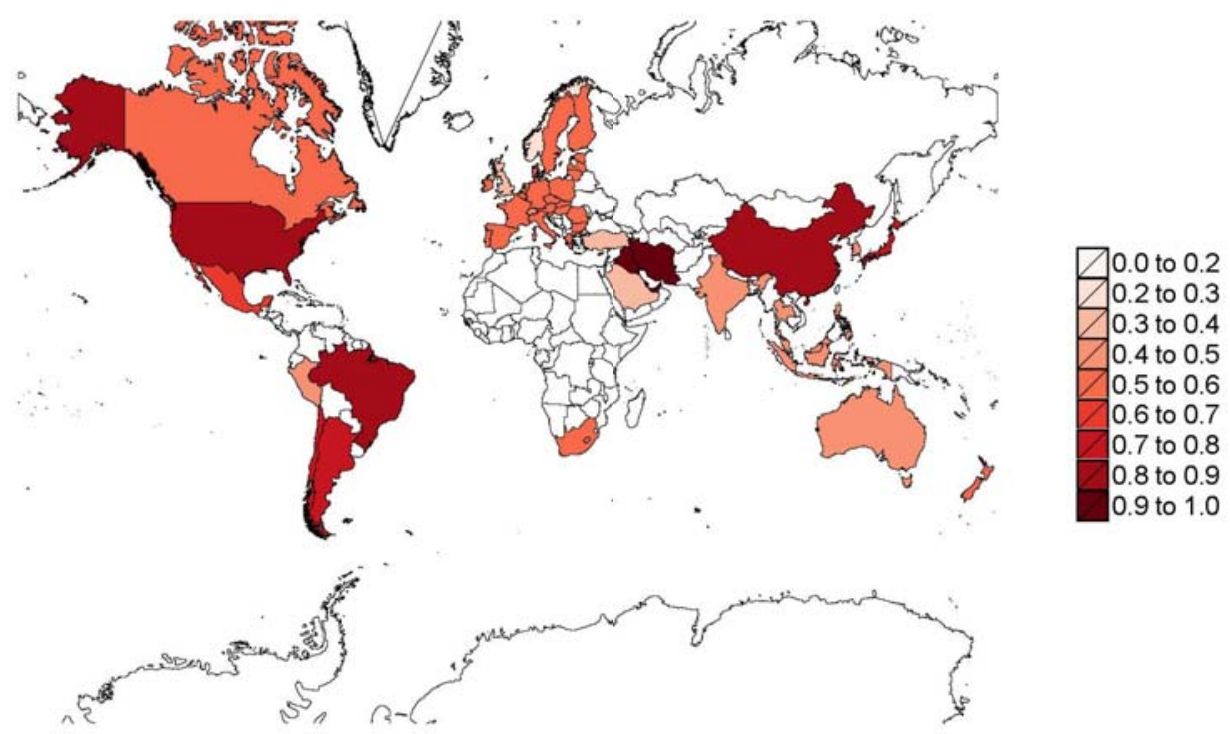

(b) $h=2$ (Figure 7 continues on the next page ...) 

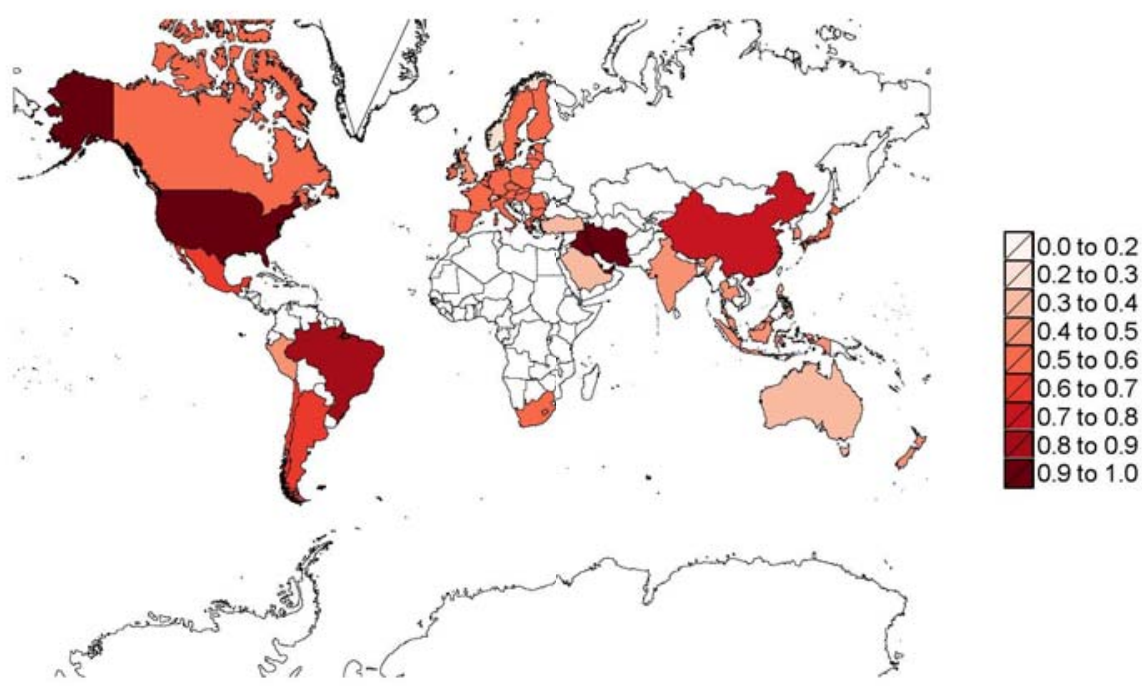

(c) $h=4$
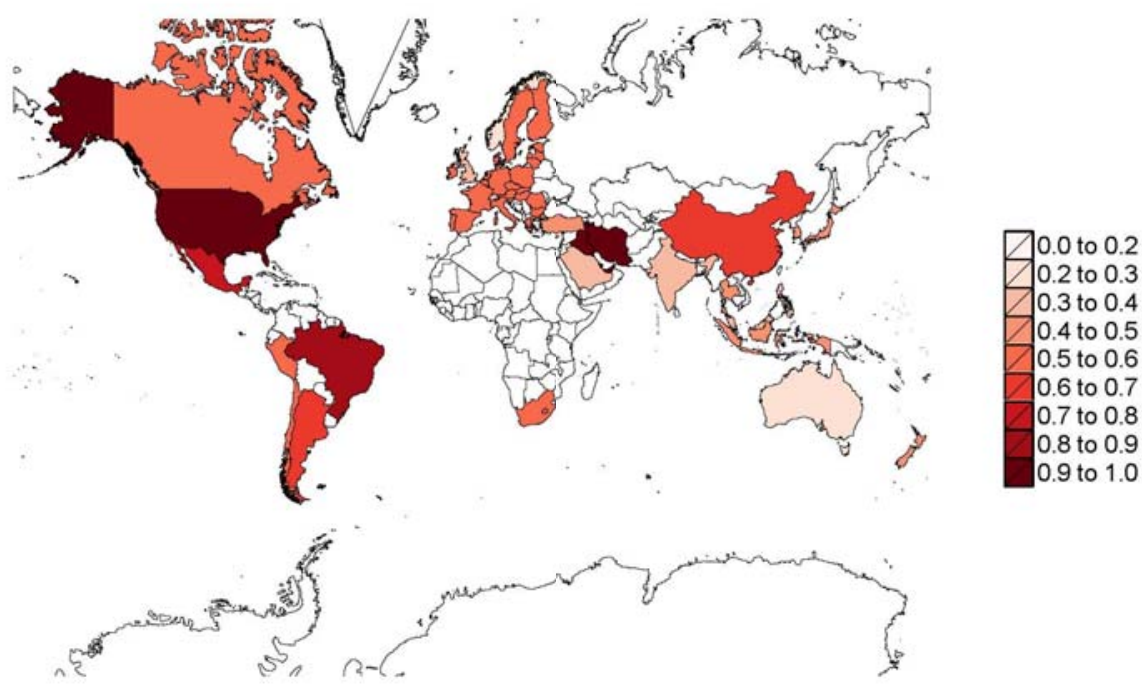

(d) $h=8$ 


\subsubsection{A Schematic Representation of Korea's Connectedness}

We follow GNS (2013b) and present the summary venn diagram of the bilateral connectedness of the Korean economy associated with the US, the EU, Japan, China, ROW and the oil price and over four quarters in Figure 8. The area of the central circle represents the Korea's own FEV contribution while the area of the six outer dircles represents the FEV contribution from the named region. All of the cirdes are on the same scale. The distance between inner and outer dirdes is inversely proportional to the to-between contribution of Korea. Note that in the case of oil, the scale is multiplied by a factor of 5 because the FEV contributions from Korea to the oil price is very weak.

The Korea's own FEV contribution is significant but weakens at longer horizons. The FEV contribution from the ROW is approximately as large as the own contribution and is the largest external factor followed by the US and the oil price. The contributions from the EU and J apan are non-negligible and of roughly the same magnitude, especially in the short term. China exerts only a modest influence on the Korean economy. The contributions from the US and the oil price strengthen over time while those from the EU and China remain relatively constant. I nterestingly, the J apanese contribution weakens as the horizon rises.

The FEV contributions to the other regions from Korea also provides an interesting pattern. Korea exerts a dominant influence on the ROW at all horizons. Similarly, it exerts a rather strong and constant effect on the EU. By contrast, the influences of the Korean economy on the US and China is relatively weak in the short term but strengthens gradually as the horizon increases. The similar timevarying pattern is observed for Japan, but the Korea's influence is much stronger. Finally, its influence on the oil price is almost negligible as expected. When comparing with the results for the US and the EU reported in GNS (2013b), we find that the FEV contributions from Korea to the other regions are generally weaker and similar to the J apanese case, reflecting that the small open economy of Korea cannot drive outcomes in the global economy. 
Figure 8: Bilateral Connectedness of Korea with Oil price, US, EU, Japan, China, and Rest of the World
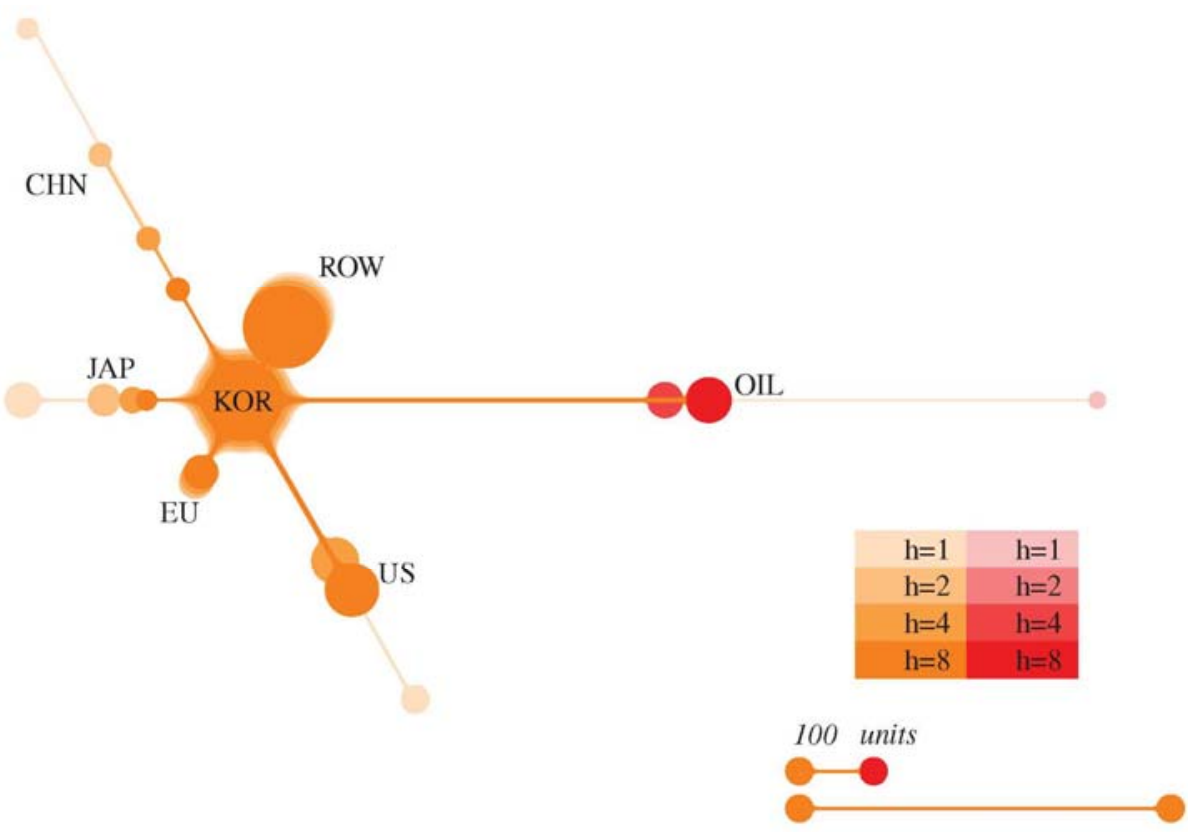

Notes: The area of the circles represents the size of the FROM contribution (the larger the area, the bigger the FROM contribution of other countries/regions to Korea). All the circles (across horizons) are normalized on the same scale such that the FROM-OWN contribution of Korea at $h=1$ equals 1 . The distance represents the inverse of TO contribution (the closer the distance, the bigger the TO contribution of Korea to other countries/regions). All the distances (across horizons) are normalized on the same scale such that the inverse of the TO contribution from Korea to ROW at $h=1$ equals 1 . The distance between KOR and the oil price has been scaled down by a factor of 5 , reflecting the fact that the Korean economy does not exert any significant influence on the global oil price. 


\subsubsection{Bilateral Connectedness of Korea with 10 Regions and the Oil Price}

Figure 9 shows the bilateral connectedness of the Korean economy with 10 regions and the oil price. This figure draws out some stylised findings which accurately capture many of the key interrelationships between Korea and the global economy. First, the largest from-between contributions are associated with the US, the oil price and ASEAN followed by the BICS, the other European countries, the ROW and the EU. As noted above, the Japanese contribution is significant only in the short run and dedines substantially at the longer horizons. Secondly, the largest to-between contributions of the Korean economy are associated with ASEAN followed by the other European countries, the ROW and the BICs. I ts influence on the EU, Oceana and Latin America are non-negligible and of roughly equal magnitude. By contrast the to-contributions to the US and the oil price are almost negligible. Combining these results together, we find that the largest (negative) net contributors are the US and the oil price, indicating that they are the most important external shock transmitters for the Korean economy. The next most significant shock transmitters are the $\mathrm{BICS}$, Japan (only in the shorter horizons) and Latin America (only in the longer horizons), albeit much weaker than the US and the oil price. On the other hand, the Korean economy exerts a significantly positive net-contribution to ASEAN followed by ROW, OEURO and OCEANA. Interestingly, the Korea's net position with the EU and J apan are al most zero except for J apan in the shorter horizons. 
Figure 9: Bilateral Connectedness of Korea with 10 Regions and the Oil Price
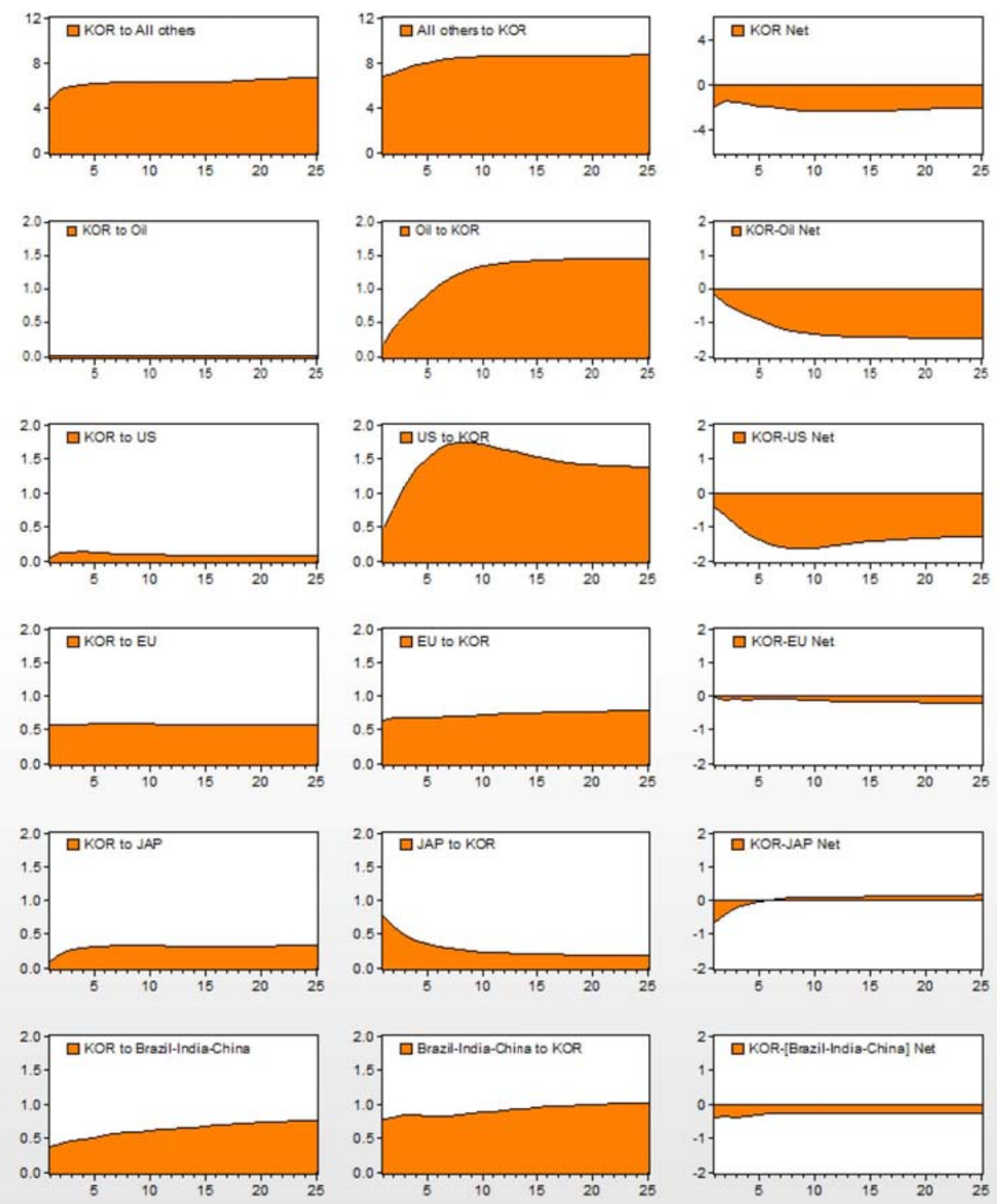

(a) (Figure 9 continues on the next page...)

Note: Bilateral connectedness of Korea represents the to-between contribution from Korea to country $i$ and the from-between contribution from country $i$ to Korea. 

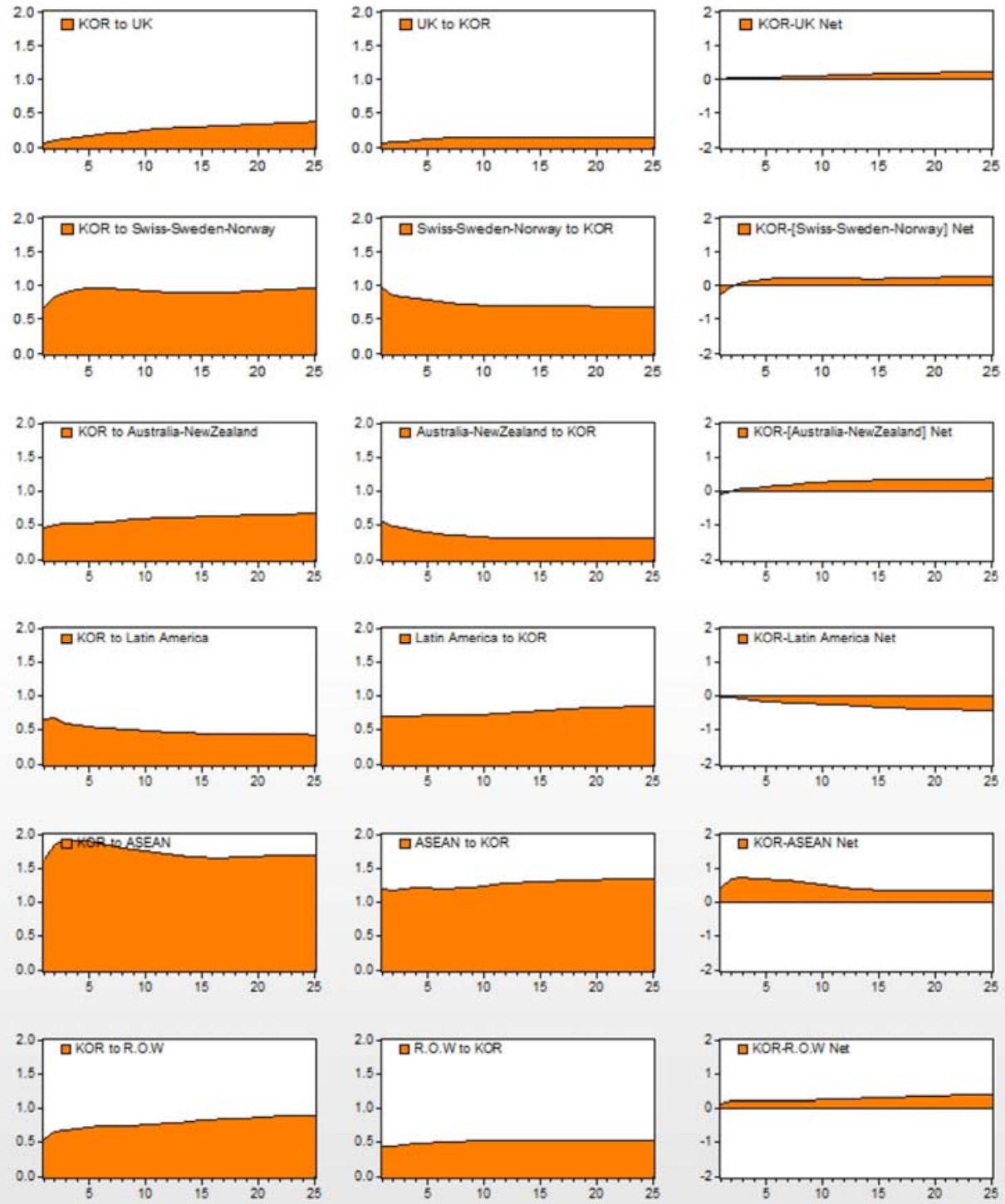

(b) (...Figure 9 continues from the previous page) 


\subsection{Recursive Sample Analysis of Spillover Dynamics, 2005-2012}

In order to further examine how the GFC affects the connectedness dynamics of the Korean economy, we employ the recursive estimation over the samples 1980q2-2005q2 to 1980q2-2012q3.

\subsubsection{TimeVarying Bilateral Connectedness of Korea with 10 Regions and Oil Price}

Here we report the time-varying estimation results for the bilateral connectedness and the associated from-transmission ratio as defined in (15). Figure 10 presents the shock transmission results at 1 quarter ahead horizon. Rather than discussing each figure in turn, we focus on the key phenomena by summarising the stylised findings surrounding the GFC period as follows: First, there has been almost no change in the connectedness structure of the Korean economy with the oil price. Secondly, interlinkages of the Korean economy has been strengthened with the advanced countries. In particular, both to-and from-contributions associated with the US significantly increase with the latter being stronger. This results in the Korea's bilateral net transmission ratio with the US being significantly more negative. Similar patterns are observed for the KoreaJ apan bilateral connectedness. Furthermore, the Korea's contributions to the EU have gradually weakened whilst the contributions from the EU do not change. As a result, the Korea's bilateral net transmission ratio with the EU turns slightly more negative. The Korea's to-contributions to BICs remain stable al beit slightly more volatile whereas the contributions from BI Cs have steadily dedined. Thus, the Korea's net transmission ratio has changed from negative to being al most negligible after the crisis. Similar, al beit weaker, patterns are observed against the Latin America. On the other hand, the from-contributions of ASEAN and the Korea's to-contributions have steadily decreased with the former being slightly stronger. As a result, Korea has maintained the slightly positive net position with ASEAN. Qualitatively similar connectedness patterns are observed against the remaining countries or regions. Thus, we can condude that the connectedness of the Korean economy with the other emerging countries or regions has slightly weakened or muted after the GFC. 
Figure 10: Time-Varying Bilateral Connectedness of Korea with 10 Regions and the Oil Price at $h=1$
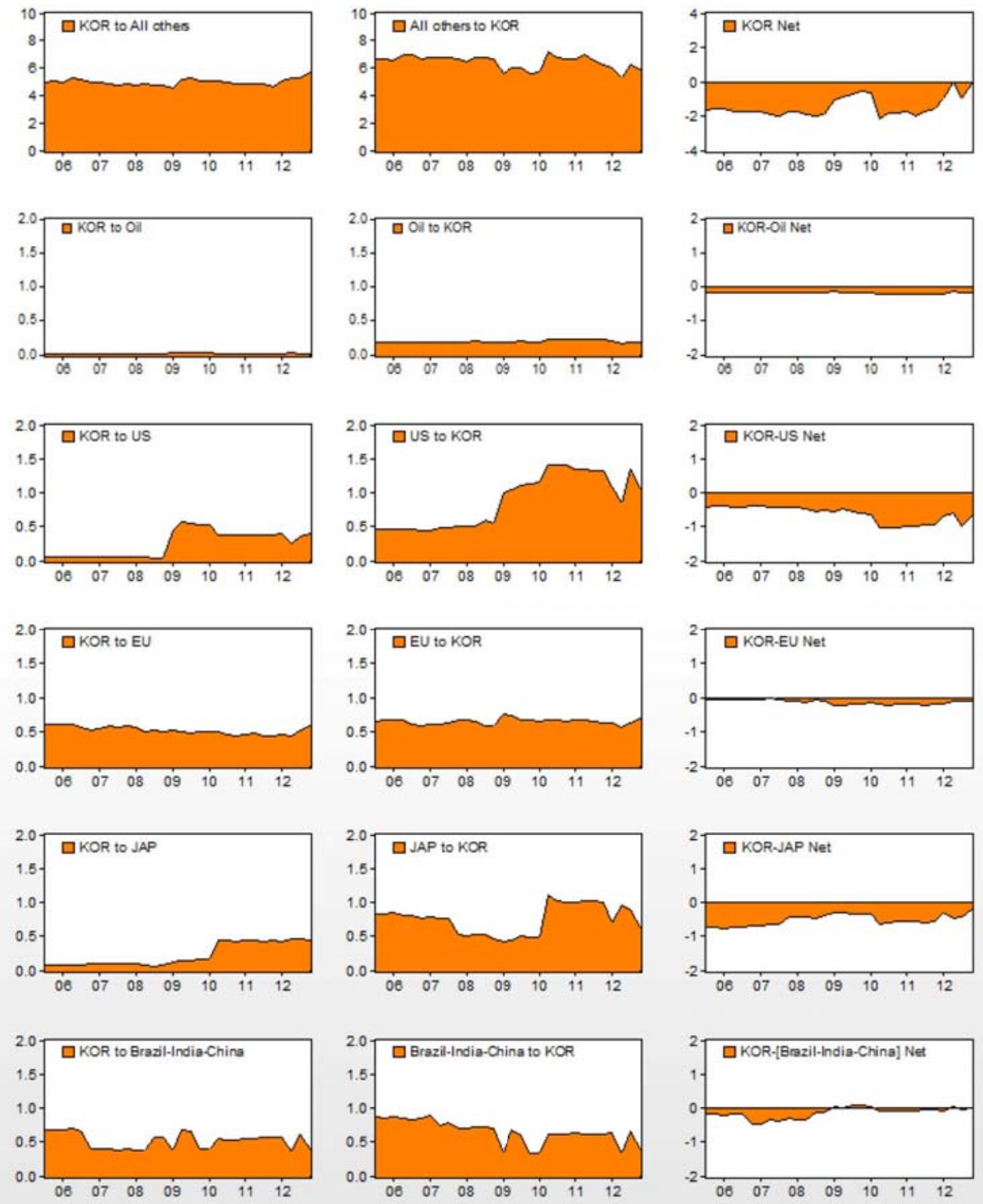

(a) $h=1$ (Figure 10 continues on the next page...)

Notes: Bilateral connectedness of Korea represents the to-between contribution from Korea to country $i$ and the from-between contribution from country $i$ to Korea. $h$ denotes the forecast horizon (quarter). 

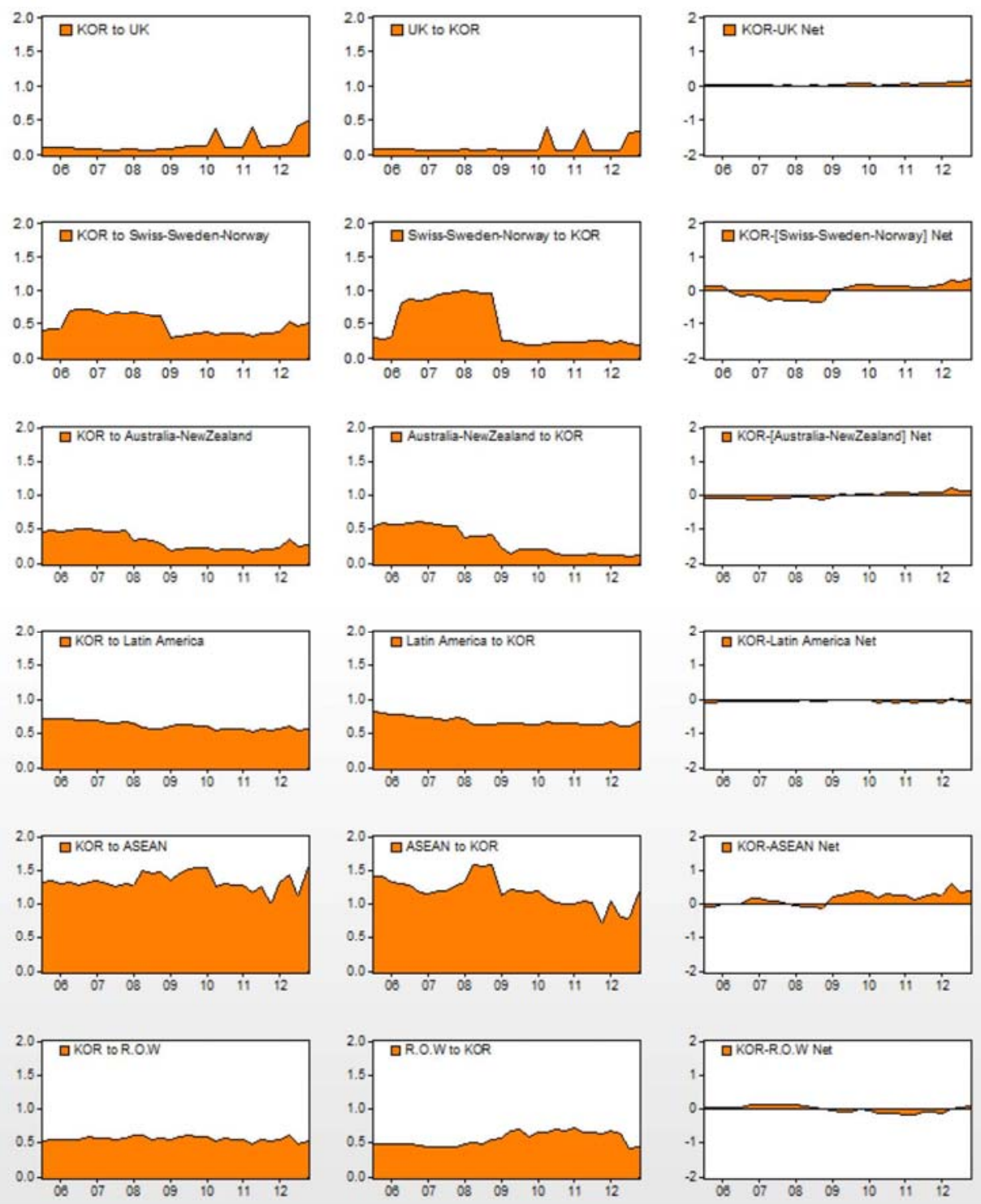

(b) $h=1$ (...Figure 10 continues from the previous page) 


\subsubsection{Time-varying FROM and TO contributions of Korean Financial and Real Variables}

We now examine how the connectedness structure of financial an real sectors in Korea has been evolved within the global economy after the GFC. Figure 11 displays the time-varying from-and to-contributions of the Korean real and financial sectors against 10 regions and the oil price at 1 quarter ahead horizon. The key stylised findings are summarised as follows: First, the connectedness of the Korean economy with the oil price has not changed. Secondly, the connectedness between financial sectors of Korea and the advanced economies (the US, the EU and J apan) has been significantly stronger after the GFC. By contrast, the connectedness of Korean financial sectors with the emerging economies has been weaker. In particular, we observe during the GFC that from-contributions of both financial and real sectors of the US and J apan have become stronger. At the same time, the to-contributions of the Korean financial and real sectors for those of the advanced economies (the US, the EU and Japan) have increased while Korea's to-connectedness with emerging economies has been muted. Somewhat surprisingly, however, the influence of the Chinese real variables has been rather muted during this period.

Overall, as expected, the GFC is associated with greater connectedness with advanced economies and reduced connectedness with emerging economies. Much of this comes from the dominant role played by stock market and exchange rate shocks stemming from the advanced economies. These results dearly highlight that crisis contagion, i.e. the rapid spread of adverse shocks from the source country to the Korean economy, has been spread particularly through the financial market channel thanks to the integrated global financial markets. Furthermore, the volatility of the global financial markets after the GFC has also been driven substantially by the monetary policy uncertainties of the advanced countries associated with the quantitative easing of the US, the EU and Japan. This may provide a partial explanation behind the increased connectedness of the Korean economy with the advance countries. On the other hand, most emerging countries have attempted to conduct the macro-prudential policies in order to stabilise their external balances, which is the partial reason behind the weakened connectedness between Korea and emerging markets. 
Figure 11: Time-Varying FROM and TO Contributions of Korean Financial and Real Variables at $h=1$

(a) FROM contributions of KOR Financial Var.
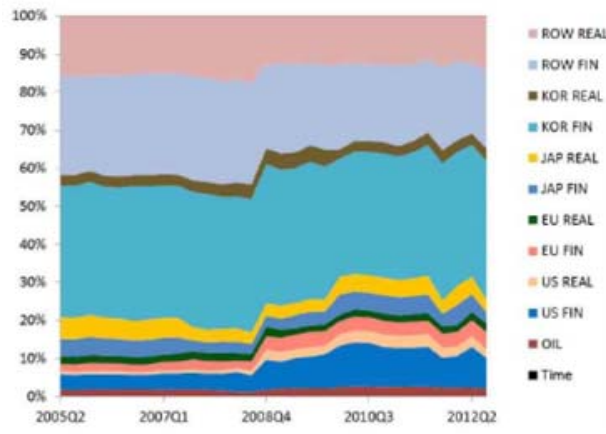

(c) TO contributions of KOR Financial Var.

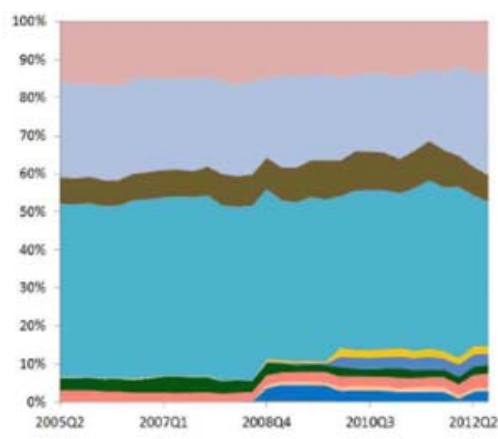

" ROW REAL
" ROW FIN
" KOR REAL
" KOR FIN
" LAP REAL
= LAP FIN
" EU REAL
" EU FIN
" US REAL
" US FIN
" OIL
- TIME

(b) FROM contributions of KOR Real Var.

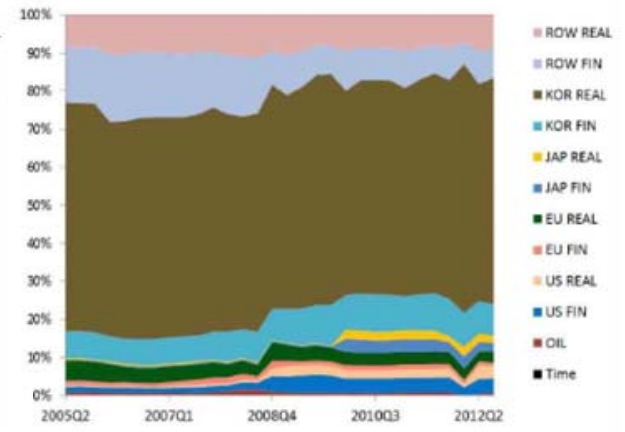

(d) TO contributions of KOR Real Var.

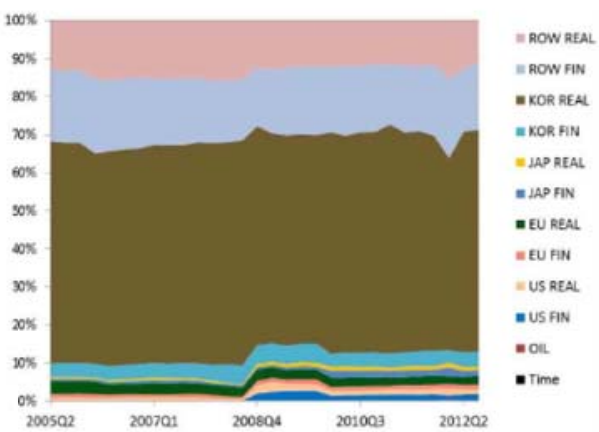




\section{Concluding Remarks}

The primary aim of this paper is to analyse complex dynamics of the connectedness structure of the small open Korean economy within the global system. This naturally requires us to develop an appropriate global model which can analyse multiple variables for multiple countries, simultaneously. For this purpose we follow the novel GVAR-GCM modeling approach, recently advanced by GNS (2012a, 2013b). By adopting the GVAR-GCM approach the proposed study can deliver important insights about these challenging issues in a flexible manner such that it would provide a promising solution to the identification of the global interlinkages of financial and real sectors of the Korean economy and the time-varying dynamics of the bilateral connectedness and spillover measurements surrounding the global financial crisis (GFC).

Our empirical analysis has been conducted in two stages. First, we evaluate the average connectedness between the Korean economy and the global economies over the pre-crisis period 1980q2-2007q2. The full sample stylised findings are summarised as follows.

First of all, we find that domestic and foreign factors exert a comparable influence on the Korean economy in the very short run but that foreign influence rapidly comes to dominate at the longer horizons. Secondly, we find that the net position is roughly balanced in terms of real sector transmission but this cannot be said of either the finandial sector or oil, where Korea is a net receiver of shocks in both cases, with Korean shocks exerting almost no effect on the oil price. Interestingly, the Korean economy is affected mostly by overseas financial conditions in the short term but it becomes more susceptible to oil price fluctuations in the long run. Thirdly, we turn to a stylised summary of GFEVDs for each of the seven Korean domestic variables. The own contribution is dominant in the short horizon but its importance falls rapidly as the horizon rises. The combined contributions of oil price, the US stock price and other foreign variables increase markedly with the horizon in all cases except the interest rate and the real exchange rate. The contribution of the oil price becomes very large in the case of real exports, equity prices and real output, but plays a much less prevalent role in 
the remaining cases. On the other hand, the contribution of the US equity price becomes substantial in the case of interest rates, equity prices, real exports, real imports and inflation. Fourth, through the analysis of the bilateral net transmission ratios associated with any individual country or region, we are able to identify that the dominant shock transmitters to the Korean economy are the US and the oil price, indicating that they are the most important external driver of the Korean economy. On the other hand, shocks within the Eurozone are not likely to be strongly transmitted to the Korean economy. An importance of China as a shock transmitter is likely to increase dramatically with its growing prominence in the global economy. Furthermore, we find that the FEV contributions from Korea to the other regions are generally weaker and similar to the J apanese case, reflecting that the small open economy of Korea cannot drive outcomes in the global economy.

We then investigate the changes in the nature and extent of connectedness brought about during the GFC by means of recursive estimation over the samples $1980 q 2-2005 q 2$ to $1980 q 2-2012 q 3$. This allows us to trace how the international linkages of the Korean economy evolved during the Great Recession. Overall, as expected, the GFC is associated with greater connectedness with advanced economies and reduced connectedness with emerging economies.

Finally, we note that our framework could easily be extended to address a range of further issues. Foremost among these must be the development of a time-varying weighting link matrix that could address issues of the recent trend that the trade shares of both China and ROW have been on the rise whilst the shares of the historically important trading partners such the US, the EU and J apan have steadily dedined. 


\section{References}

Anderson, R., H. Qian, and R. Rasche, (2006), "Analysis of Panel Vector Error Correction Models Using Maximum Likelihood, the Bootstrap, and Canonical-correlation Estimators," Working Paper 2006-050A, Federal Reserve Bank of St. Louis.

Assenmacher-Wesche, K., and S. Gerlach, (2008), "Monetary Policy, Asset Prices and Macroeconomic Conditions: A Panel VAR Study," Working Paper No. 149, National Bank of Belgium.

Bussiere, M., A. Chudik, and G. Sestieri, (2009), "Modelling Global Trade Flows: Results from a GVAR Model," Working Paper No. 1087, European Central Bank.

Canova, F., M. Ciccarelli, and E. Ortega, (2007), "Similarities and Convertgence in G-7 Cydes," Journal of Monetary Economics, Vol. 54, pp. 850-878.

Carabenciov, I., I. Ermolaev, C. Freedman, M. Juillard, O. Kamenik, D. Korshunov, D. Laxton, and J. Laxton, (2008), "A Small Quarterly MultiCountry Projection Model," Working Paper No. 08/279, International Monetary Fund.

Chen, Q., D. Gray, P. N'Diaye, H. Oura, and N. Tamirisa, (2009), "I nternational Transmission of Bank and Corporate Distress," Working Paper No. WP/10/124, International Monetary Fund.

Choi, Y.J., J. Choi, and M. Park, (2011), "The Effects on Economic Growth of Sharp Rises in Capital Inflows," Bank of Korea Monthly Bulletin, June 2011, pp. 24-54 (Korean).

Choi, B., D. Kim, and S. Ahn, (2013), "Results of the Reconstruction of the VAR Model Block of the BOKs Macroeconomic Modelling System," Bank of Korea Monthly Bulletin, November 2013, pp. 15-38 (Korean).

Ciccarelli, M., E. Ortega, and M.T. Valderrama, (2012), "Heterogeneity and Cross-country Spillovers in Macroeconomic-Financial Linkages," Working Paper No. 1498, European Central Bank.

Dees, S., F. di Mauro, M.H. Pesaran, and L.V. Smith, (2007), "Exploring the International Linkages of the Euro Area: A Global VAR Analysis," Journal of 
Applied Econometrics, Vol. 22, pp. 1-38.

Dees, S., S. Holly, M.H. Pesaran, and L.V. Smith, (2007), "Long Run Macroeconomic Relations in the Global Economy," Economics The Open-Access, Open-Assessment E-Journal, Vol. 3, pp. 1-56.

Diebold, F.X., and K. Yilmaz, (2009), "Measuring Financial Asset Return and Volatility Spillovers, with Application to Global Equity Markets," Economic Journal, Vol. 119, pp. 158-171.

Diebold, F.X., and K. Yilmaz, (2014), "On the Network Topology of Variance Decompositions: Measuring the Connectedness of Financial Firms," Journal of Econometrics, forthcoming.

Eichengreen, B., A. Mody, M. Nedeljkovic, and L. Sarno, (2012), "How the Sub-prime Crisis Went Global : Evidence form Bank Credit Default Swap Spreads," Journal of I nternational Money and Finance, Vol. 31, pp. 1299-1318.

Fong, T., and A. Wong, (2012), "Gauging Potential Sovereign Risk Contagion in Europe," Economics Letters, Vol. 115, pp. 496-499.

Goodhart, C., and B. Hofmann, (2008), "House Prices, Money, Credit, and the Macroeconomy," Oxford Review of Economic Policy, Vol. 24, pp. 180-205.

Greenwood-Nimmo, M.J., V.H. Nguyen, and Y. Shin, (2012a), "Probabilistic Forecasting of Output Growth, I nflation and the Balance of Trade in a GVAR Framework," Journal of Applied Econometrics, Vol. 27, pp. 554-573.

Greenwood-Nimmo, M.J., V.H. Nguyen, and Y. Shin, (2012b), "International Linkages of the Korean Economy: The Global Vector Error-Correcting Macroeconometric Modelling Approach." Journal of Market Economy, Vol. 41, pp. 15-64.

Greenwood-Nimmo, M.J ., V.H. Nguyen, and Y. Shin, (2013a), “Using Global VAR Models for Scenario-Based Forecasting and Policy Analysis." In F. di Mauro and M.H. Pesaran (Eds.) The GVAR Handbook: Structure and Applications of a Macro Model of the Global Economy for Policy Analysis. pp. 97-113. Oxford: OUP.

Greenwood-Nimmo, M.J., V.H. Nguyen, and Y. Shin, (2013b), "Measuring the Connectedness of the Global Economy," mimeo, University of Melbourne. International Monetary Fund (2009), "Responding to the Financial Crisis and 
Measuring Systemic Risk," Global Financial Stability Report, April.

Kim, Y., and J.Y. Park, (2009), "Foreign I mpulse Response Analysis for Korea in a

Global Structural VAR Model," Kyong Je Hak Yon Gu, Vol. 57, pp. 5-37 (Korean).

Pesaran, M.H. (2013), “Testing Weak Cross-Sectional Dependence in Large Panels," mimeo, University of Cambridge.

Pesaran, M.H., T. Schuermann, and S.M. Weiner, (2004), "Modeling Regional Interdependencies Using a Global Error-Correcting Macroeconometric Model," Journal of Business and Economic Statistics, Vol. 22, pp. 129-162.

Pesaran, M.H., and Y. Shin, (1998), "Generalized Impulse Response Analysis in Linear Multivariate Models," Economics Letters, Vol. 58, pp. 17-29.

Pesaran, M.H., and R.P. Smith, (2006), "Macroeconomic Modelling With A Global Perspective," The Manchester School, Supplement, pp. 24-49.

Sgherri, S., and A. Galesi, (2009), "Regional Financial Spillovers Across Europe: A Global VAR Analysis," Working Paper No. 09/23, I nternational Monetary Fund. Shin, Y. (2009), "The Cointegrating VAR Modelling Approach to the Korean Macroeconomy in the Presence of Structural Breaks," The Korean Journal of Economics, Vol. 16, pp. 175-241.

Taylor, J.B. (1993), "Discretion versus Policy Rules in Practice," Carnegie Rochester Conference Series on Public Policy, Vol. 39, pp. 195-214. 


\section{$<$ Abstract in Korean $>$}

\section{박하일*, 신용철**}

글로벌 금융위기 이후 국가 간 금융 및 거시경제의 상호연계성이 높아짐에 따 라 글로벌 충격 등이 개별국가에 파급되는 경로와 그 효과를 분석하는 것이 중요 하다는 인식이 확산되고 있다. 이에 따라 본고는 Global VAR모형을 설정하여 우 리나라가 금융 및 실물측면에서 글로벌 경제와 가지는 국제연계성을 파악하고, 이를 통해 글로벌 충격이 우리나라에 미치는 파급효과를 분석하였다. 분석 결과 미국, 유럽, 중국, 아세안 국가의 금융·실물변수와 우리나라 금융·실물변수 간 연 계성이 높게 나타난 가운데 국제유가도 우리경제에 미치는 영향이 상당한 것으로 분석되었다. 해외 변수 중에서는 특히 미국 주가가 우리나라의 주가, 금리 등 금융 변수뿐만 아니라 수출입, 인플레이션 등에 미치는 파급효과도 큰 것으로 나타났 다. 또한 국제유가는 우리나라의 수출 및 경제성장은 물론 주가에 미치는 영향력 도 큰 것으로 나타났다. 한편 글로벌 금융위기 이후에는 선진국의 금융변수가 우 리나라에 미치는 영향력이 확대되고 있으며, 신흥국의 영향력은 다소 감소하였으 나 절대 비중은 여전히 큰 것으로 분석되었다. 따라서 글로벌 금융불안정이 국내 금융 및 거시경제로 파급되는 경로를 면밀히 점검함으로써 우리경제 전체의 복원 력을 강화화기 위한 효과적인 방안을 지속적으로 강구할 필요가 있다.

* 한국은행 경제연구원 국제경제연구실 선임연구원

** University of York 경제학과 교수

연구내용은 집필자의 개인의견이며 한국은행의 공식견해와는 무관합니다. 따라서 본 논문의 내용을 보도 하거나 인용할 경우에는 집필자명을 반드시 명시하여 주시기 바랍니다. 